أثر سعر الصرف على قيم التداول بالبورصة المصرية تطبيق على سوق الأولق المالية المصرية

\author{
الباحث: (1) - n \\ د.إسلام نمير رامي سيد \\ عضو هيئة تدريس بقسم إدارة الأعمال بمعهد العبور العالي للإدارة والحاسبات \\ ونظم المعلومات
}

\title{
الملخص
}

هدفت الدراسـة لمعرفة أثر سـر الصـرف على قيم تداولات قطاعات البورصـة المصرية

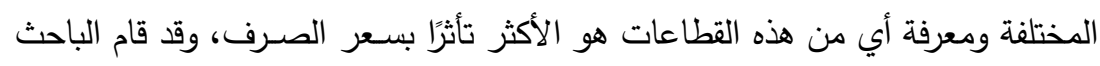

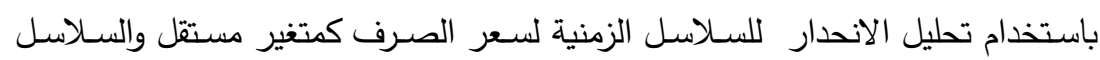

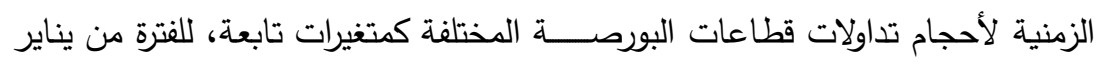

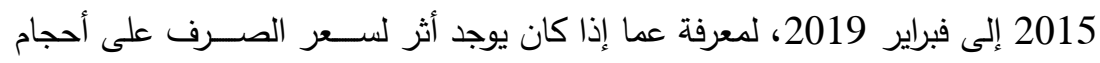

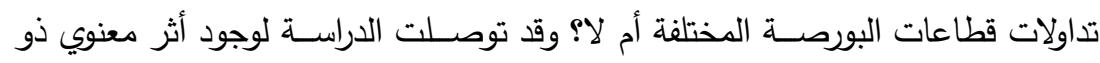

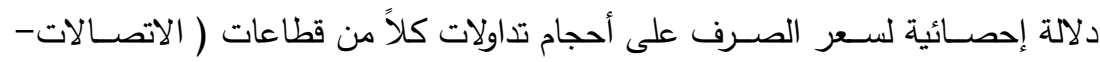

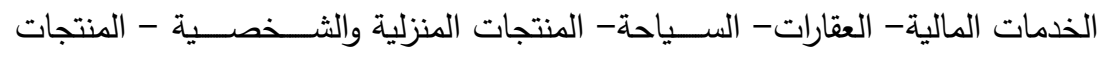

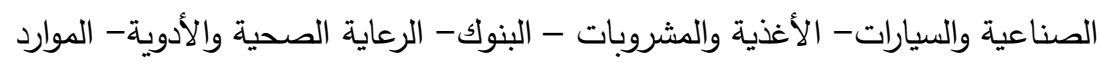

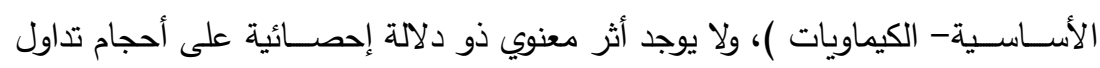
قطاع التشييد والبناء وذلك عند مستوى معنوية 5\%، وقد وجد أن أكتر القطاعات ارتباطًا

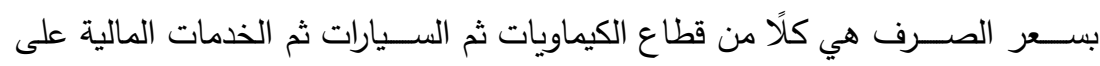
التوالى. 


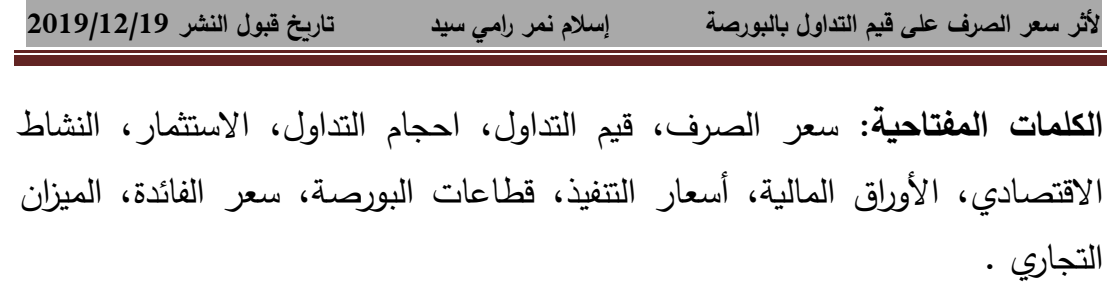

\begin{abstract}
The study aimed to find out the impact of the exchange rate on the trading values of the different sectors of the Egyptian Stock Exchange and to find out which of these sectors is most effected by the exchange rate. The researcher used regression analysis of the time series of the exchange rate as independent variable and the time series of the trading volumes of the various exchanges sectors as dependent variables، for the period from January 2015 To February 2019، to know whether there is an impact of the exchange rate on the trading volumes of different sectors of the stock market or not? The study has found a significant impact of the exchange rate on the volumes of each of the next sectors (telecommunications - financial services - real estate - tourismHousehold \& Personal Products - Industrial \& Automotive Products - Food \& Beverages - Banks - Healthcare \& Pharmaceuticals - Basic Resources - Chemicals). There is no significant effect on the trading volume of the construction sector at a significant level of 5\%. It has been found that the most closely related sectors to the exchange rate are the chemicals، automotive and financial services sectors respectively.
\end{abstract}

Keywords: exchange rate، trading values, trading volume, investment, economic activity, securities, execution prices, stock exchange sectors, interest rate, trade balance. 


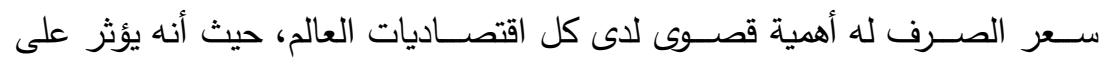

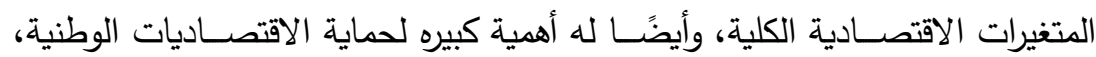
حيث أنه احد أهم أدوات السياسة النقدية للبلدان ويؤثر على كل المتغيرات الاقتصادية الكلية (دوحه,2015,ص2) ولا يؤثر فتط في متغيرات الاقتصـــاد الكلى، ولكن يؤثر

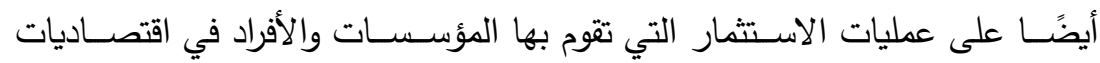
الدول، ليس فقط في الاستثمار المباشر ولكن في الاستثمار غير المباشر أيضًأ في

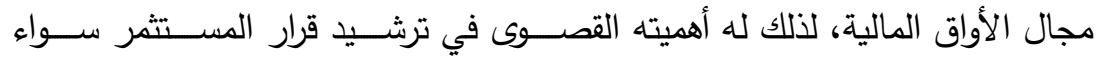
المؤسسى أو المستثمر الفرد، خصوصًا في حالة عدم استقرار سعر الصرف وتقلبه المستمر أو حتى تغيير السياسة المتبعة في تحديد سعر الصرف من عملية تسعير

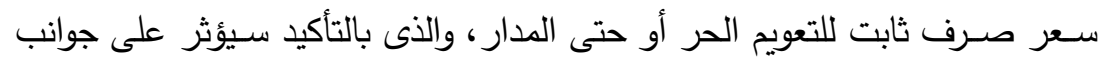

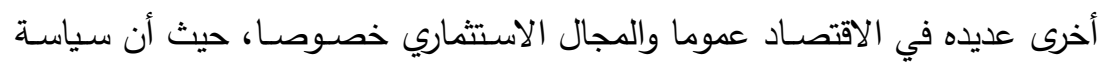

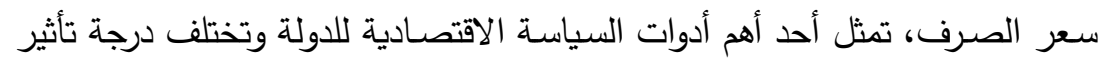

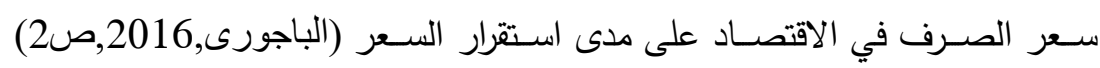

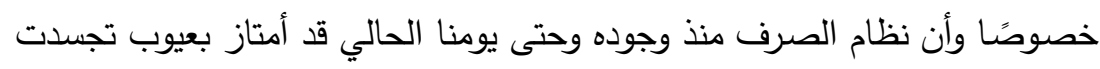

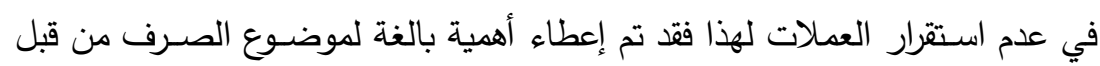

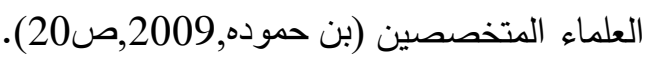
ومن أهم الجوانب التي تؤثر في عملية اتخاذ القرار الاسـتثماري في مجال البورصــة

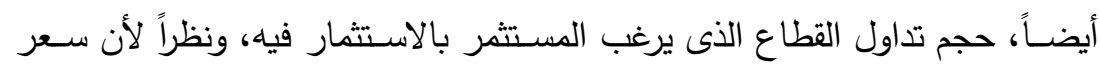
الصـرف وتقلبه من أدوات السـياسـة النقدية المهمة، كان من الضـروري معرفة تأثيره

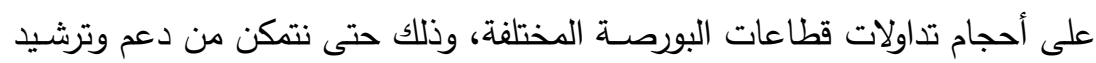
عملية اتخاذ القرار الاستثماري للمتداولين بالبورصة. 


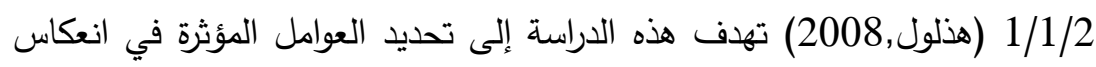
التحركات في أسعار صرف العملات الأجنبية على مؤشرات الأسعار المحلية في

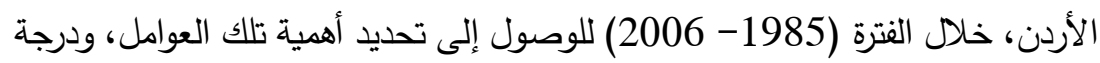
تأثيرها، وسرعة انتقالها إلى مؤشرات الأسعار المحلية.

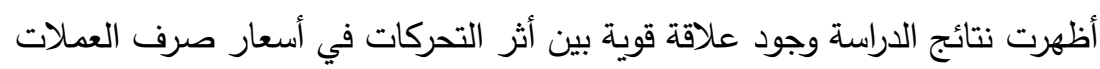

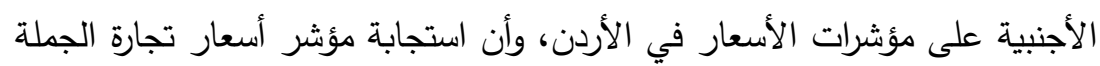

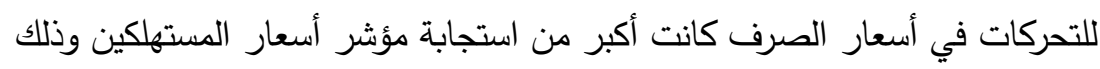

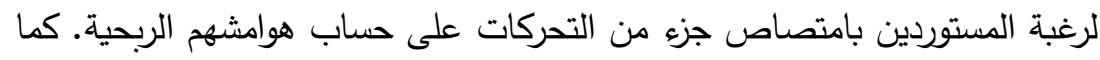

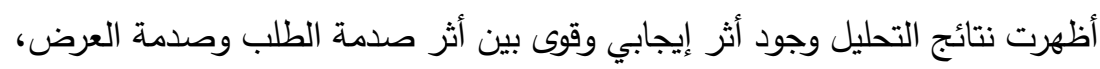

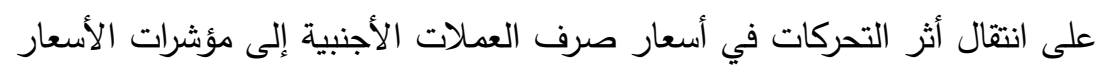
المحلية في الأردن.

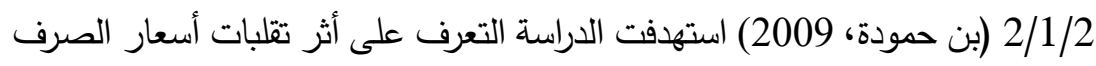

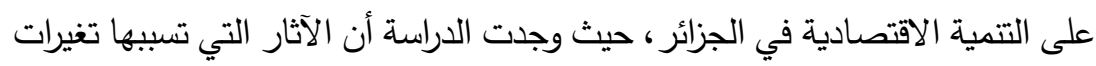

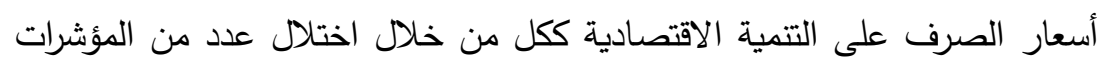

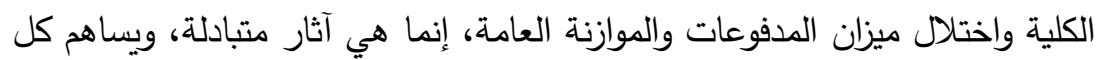

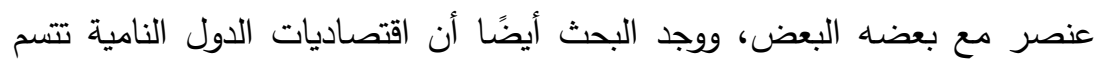
بسياسة نقدية ضعيفة وغير قادرة على رفع معدلات التنمية.

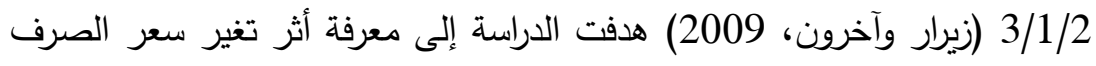

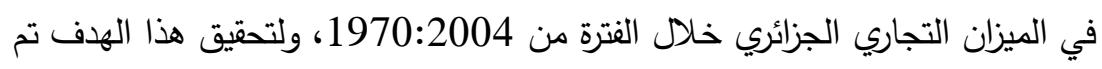

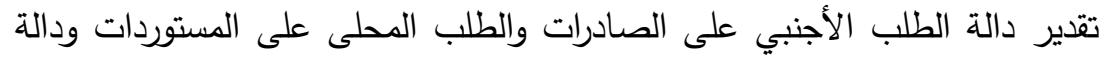
الحساب الجاري باستخدام طريقة المربعات الصغرى العادية الدصححة كليًا والمستندة 
إلى اختيار التكامل المشترك، وقد أوصت الدراسة بناءًا على نتائجها بضرورة الاهتمام

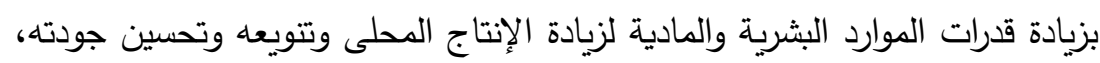
من أجل خلق وضع تتافسي أفضل. 4/1/2 (خرباش,2010) يهدف هذا البحث إلى معرفة أثر مخاطر سعر الصرف على أداء محفظة الأوراق المالية في بورصتي عمان والسعودية، ودراسة إمكانية تطبيق النظريات الحديثة في مجال إدارة محافظ الأوراق المالية، كما يهدف البحث ولئ إلى إبراز أهمية التتويع الدولي في تدنية مخاطر سعر الصرف الذى يعد من المخاطر النظامية

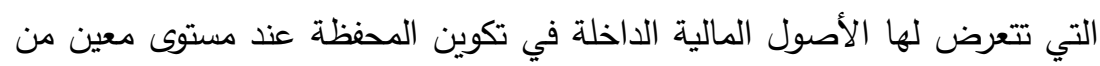
العوائد. وعلى هذا الأساس، تم اختيار عينة الدراسة من أسهم أفضل الشركات المدرجة في كل من بورصة عمان والسعودية خلال عام 2010. وقد خلصت الدراسة إلى أن كل من عدد الأوراق المالية الداخلة في تكوين المحفظة وكذا معاملات الارتباط فيما بينها، بالإضافة إلى استراتيجية التتويع الدولي، تساهم في التي تدنية مخاطر سعر الصرف إلى أدنى مستوى لها مع تحقيق مستوى مقبول من العوائد. 5/1/2 5 ( الساعدى وعبد, 2011 ) تتاول هذا البحث الأثر الذى يمكن أن يتركه

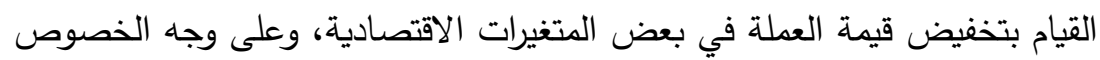

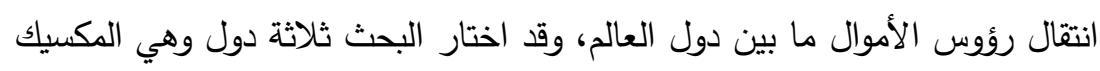
والباكستان وكينيا كعينة له، حيث قامت هذه الدول بتخفيض قيم دول عملاتها بأوقات

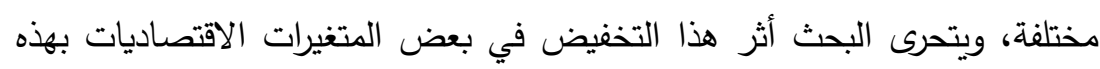

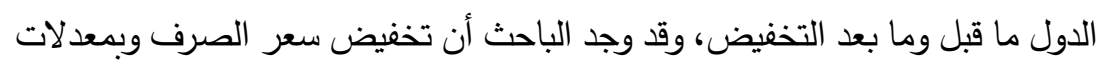

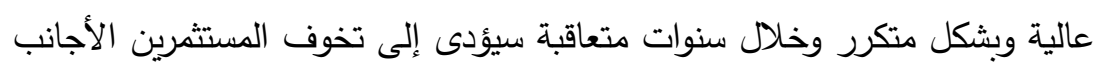

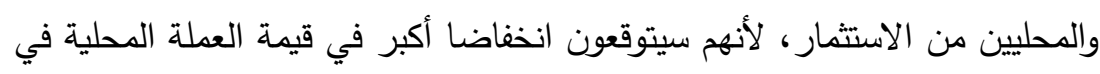

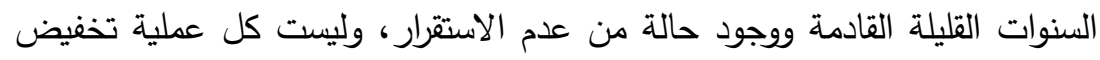

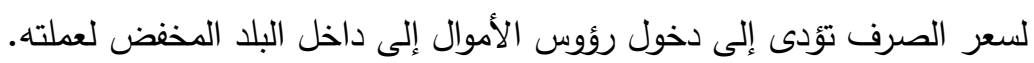


6/1/2 ( الأسدى والربيعي، 2013 ) استهدف البحث تحليل العلاقة بين تحركات أسعار الصرف وانعكاس ذلك على النمو الاقتصادي في ظل تحرير التجارة الخارجية

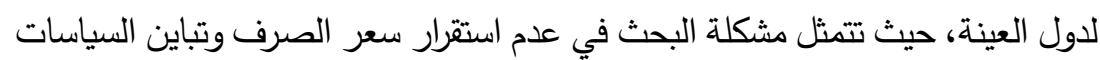

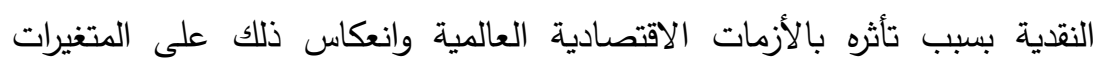
الاقتصادية، وقد وجدت الباحثتان أن التغير في سعر الصرف يساهم في تحويل الموارد بين القطاعات، والذى يؤدى بدوره في تطوير صناعات معينة أو تعيل فروع صناعية

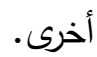

7/1/2 ( دوحة، 2015 ) استهدفت الدراسة محاولة دراسة أثر سلوك سعر الصرف

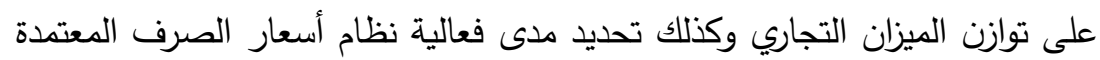
في التخفيض من العجز في الميزان التجاري، حيث تمثلت إثكالية البحث الرئيسية في معرفة ما هو أثر تقلبات سعر الصرف على الميزان التجاري وما هي سبل علاجها تصنا في الجزائر، وقد توصلت الدراسة إلى وجود علاقة طردية بين سعر الصرف ورصيد الميزان التجاري وكذلك وجود علاقة طردية بين تطورات أسعار البترول ورصيد الميزان التجاري.

8/1/2 ( الداوى، 2015 ) استهدفت هذه الدراسة قياس الأثر الكمي لعملة الدولار

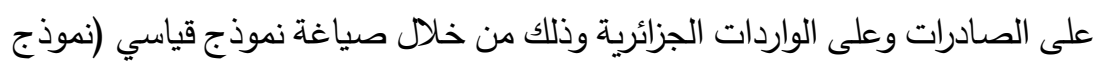

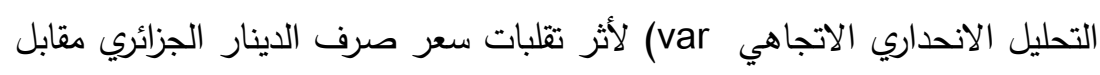

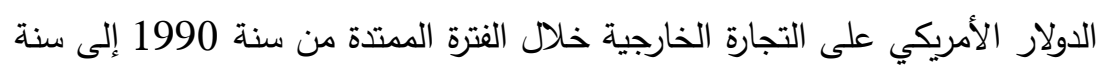

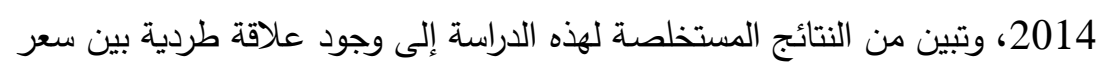
الصرف والصادرات وسعر الصرف والواردات. 9/1/2 استخدمت هذه الدراسة المنهج التحليلي في بيان تأثير الفروق في أسعار صرف الجنيه

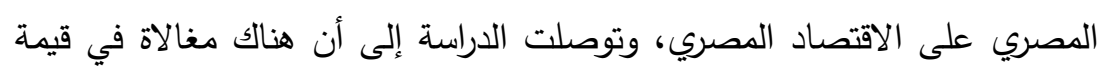

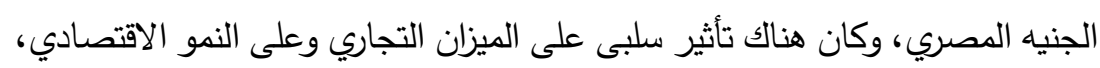


وتأثير إيجابي على البورصة المصرية، لإزالة القيود على الودائع الدولارية والسحب

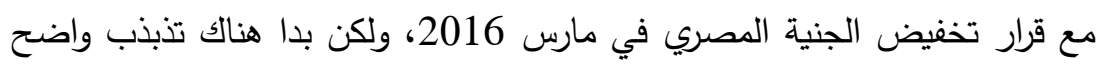
بين الارتفاع والانخفاض في مؤشر البورصة المصرية، وهذا ناتج من الفروق السعرية

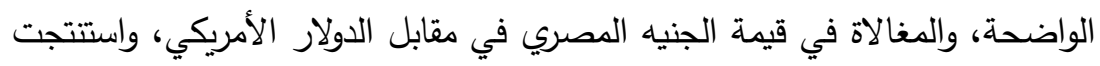

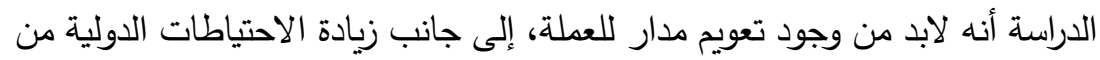
العملات الأجنبية، مع توفير بيئة جاذبة للاستثمار وترشيد الإنفاق الحكومي.

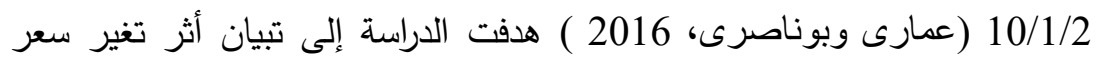
الصرف على الاقتصاد الجزائري، حيث تمثلت إثكالية البحث الرئيسية في معرفة إلى تئى إنى أي مدى تؤثر تقلبات أسعار الصرف على ميزان المدفوعات الجزائري، وقد خلصت الدراسة إلى أن سعر الصرف يعتبر أداة لإعادة توازن ميزان المدفوعات من خلاتل

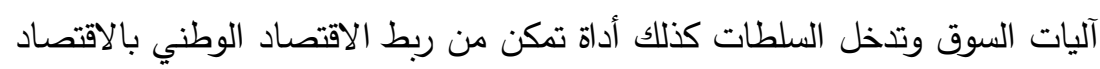

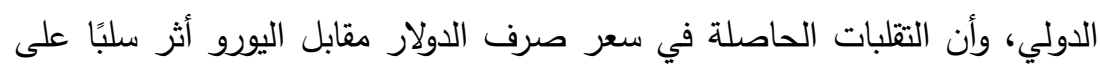
الاقتصاد الجزائري. 11/1/2 ( زراقة، 2016 ) هدفت الدراسة إلى تحديد العلاقة التبادلية بين أسعار الصرف وميزان الدفوعات بمكوناته المختلفة إضافة إلى تحديد الآثار المحتملة لكليهما

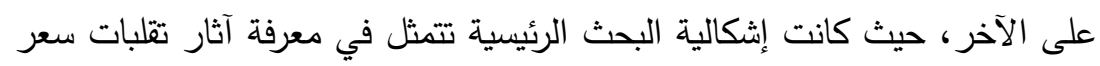
صرف الدينار الجزائري على رصيد الميزان التجاري، وتوصلت الدراسة إلى أن آلية الصرف تعتبر من أهم الآليات التي تعمل على إعادة التوازن إلى ميزان المدفوعات.

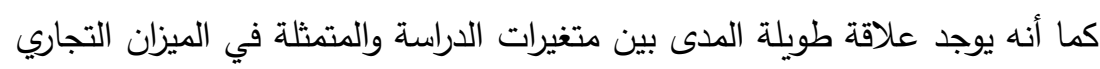

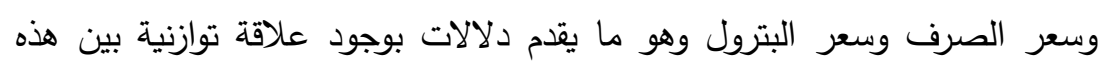
المتغيرات خلال فترة الدراسة. 12/1/2 ( منصور،2019) هدفت الدراسة إلى التعرف على أثر تحرير سعر الصرف الصناف على ميزان المدفوعات والصادرات والمستوى العام للأسعار والاحتياطي النقدي والاستثمار الأجنبي، وقد توصلت الدراسة إلى أن قيام الدولة بتحرير عملتها وتركها 
للعرض والطلب، يؤدى إلى حدوث توازن تلقائي في ميزان المدفوعات، وأن الاستثمار

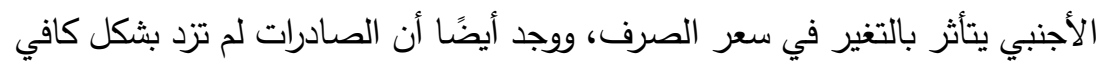
بعد تحرير سعر الصرف.

\section{2/2/2/لاراسات الأجنبية:}

1/2/2 1 Auboin and Ruta, 2011 ) تستعرض هذه الدراسة مجموعة واسعة من : الأدبيات الاقتصادية عن العلاقة بين صرف العملات والتجارة، وعلى وجه التحديد، تم

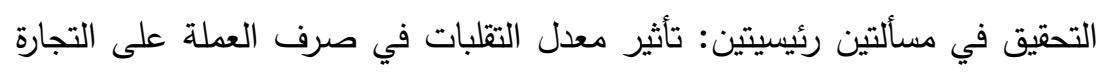
الدولية، وقد وجد أن تقلب سعر الصرف لديه تأثير سلبي (حتى إن لم يكن كبيرًا)

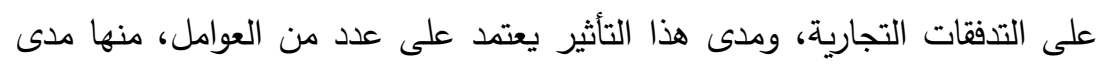

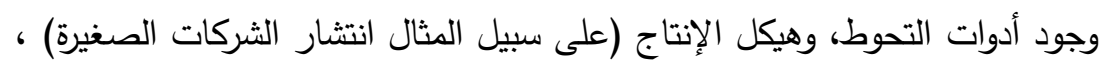
ودرجة التكامل الاقتصادي عبر البلدان. التقلبات في سعر الصرف من المتوقع أن يكون لها تأثيرات قصيرة المدى على التجارة

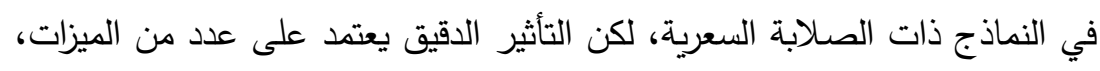

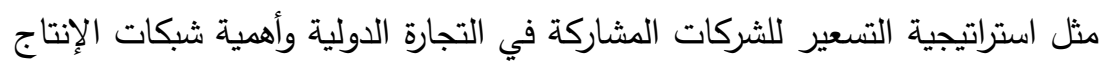
العالمية. من المتوقع أن يختفي هذا التأثير على المدى الطويل، ما لم يكن هناك بعض لتصني

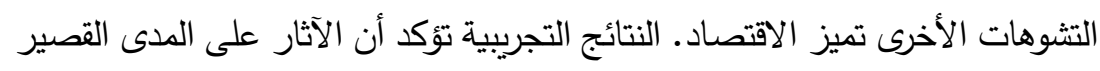
من المكن أن تكون موجودة. 2/2/2 (Musyoki, et al, 2012 ) تبحث هذه الدراسة تأثير تقلب سعر الصرف الحقيقي على النمو الاقتصادي لكينيا. استخدمت الدراسة نموذج الانحدار الذاتي

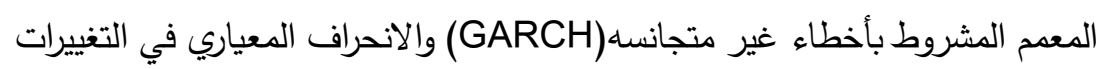

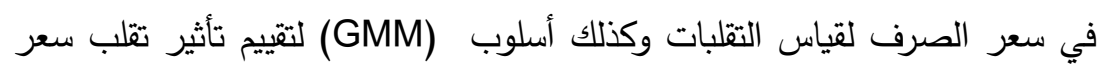
الصرف الحقيقي على النمو الاقتصادي للفترة من يناير 1993 إلى ديسمبر 2009.

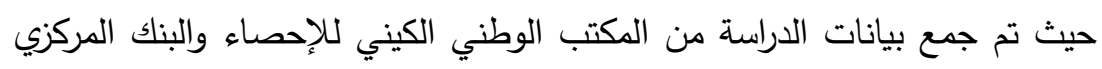
الكيني وقاعدة بيانات صندوق النقد الدولي عن طريق أخذ القيم الثهرية. وجدت ليات 
الدراسة أن معدل الصرف الحقيقي كان تقلبه شديد لفترة الدراسة بأكملها. وظهر أن سعر الصرف الحقيقي لله اتجاه عام متقلب، مما يعني أنه بصفة عامة التتافسية

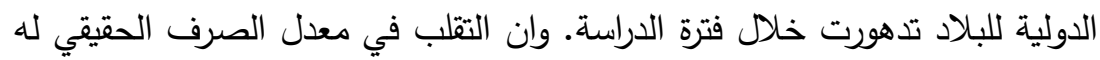
تأثير سلبي على النمو الاقتصادي في كينيا. 3/2/2 (Amador, et al, 2013 ) لقد تميزت الأزمة المالية الأخيرة بتدخلات غير لئير مسبوقة للسياسة النقدية للبنوك المركزية بقصد تحقيق الاستقرار في الأسواق المالية

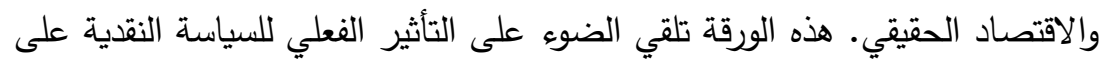

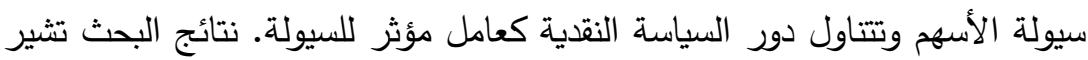

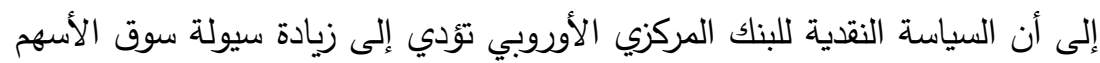

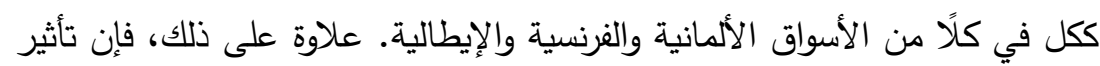
السياسة النقدية كبير على الأسهم الأصغر، مما يثير إلى تأثير غير خطي اللى السياسة النقدية على سيولة الأسهم. 4/2/2 ( Cassino and Oxley, 2013 ) درست هذه الورقة البحثية العلاقة بين تحركات سعر الصرف والاقتصاد الحقيقي - وهو مجال كان محور نقاش كبير في

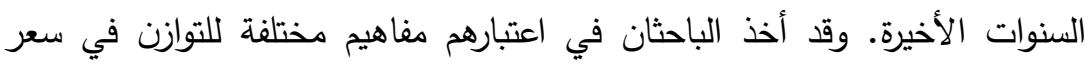
الصرف، وراجعا الأدلة الحديثة على ما إذا كان سعر صرف الدولار النيوزيلندي يمثل فئل

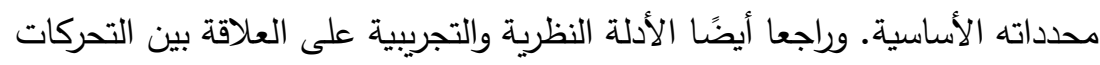

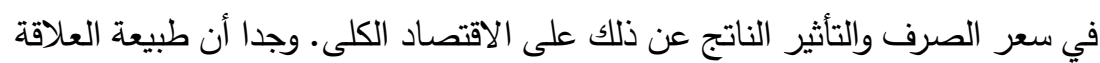
بين التحركات في سعر الصرف والتعديل الناتج في الاقتصاد الحقيقي يعتمد على الصى

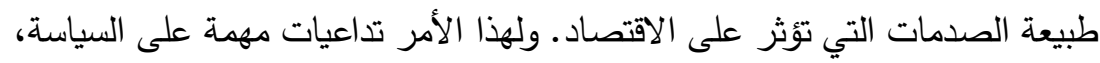

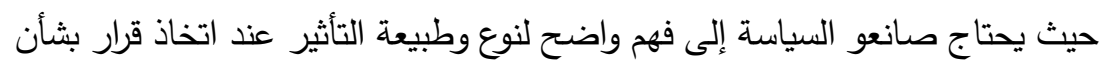

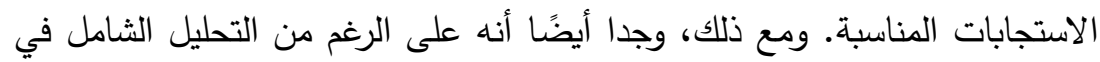

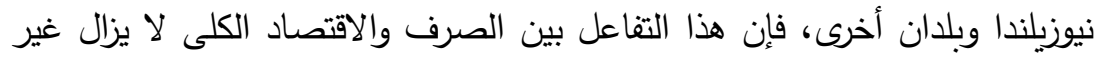

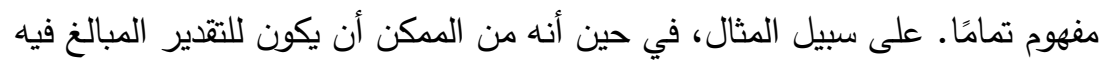


لسعر الصرف تأثير سلبي على الأداء الاقتصادي الأوسع، إلا أن الأدلة التجريبية

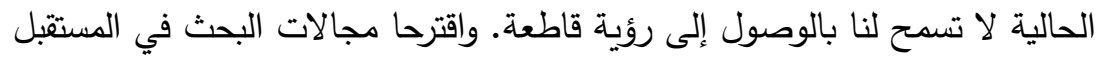

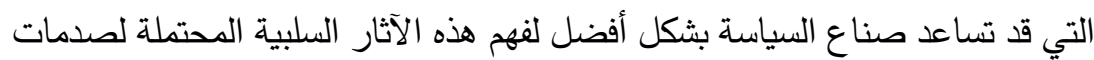
سعر الصرف على الاقتصاد الكلى.

5/2/2 (Korkmaz,2015) في هذه الدراسة، تم ذكر أنظمة سعر الصرف. باستخدام البيانات السنوية للفترة 2002-2011 من تسع دول أوروبية تم اختيارها عشوائيًا،

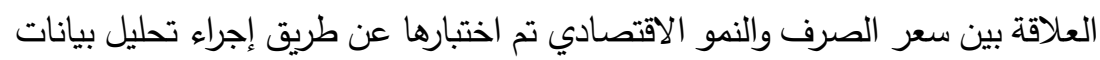
اللوحة. حيث أنه منذ العصور القديمة، تبادل البشر البضائع باستمرار لتلبية

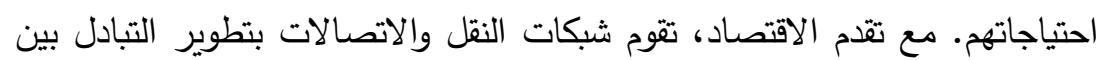

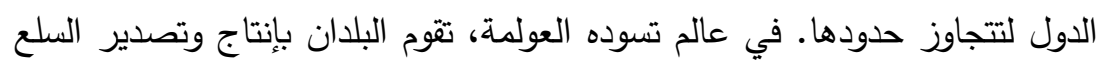
التي تتمتع بميزة في القوة الإنتاجية واستيراد البضائع التي تحتاجها. المال هو الأداة

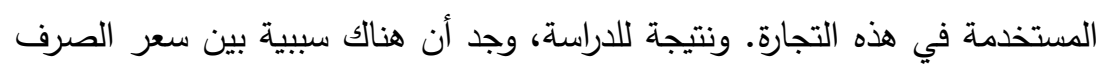
والنمو الاقتصادي للدول التسع الأوروبية. 6/2/2 (Twarowska, 2015) الهدف من هذه الورقة هو التحقق من تأثير سعر الاوربة الصرف على التجارة الخارجية لبولندا، وخاصة على الحركة التجارية الثنائية بين بولندا ومنطقة اليورو، التي هي شريك تجاري رئيسي لها. البحث يتحقق من المفاهيم النظرية التي توضح كيف يؤثر سعر الصرف على معدل دوران التجارة. وقد تم إتباع التحليل

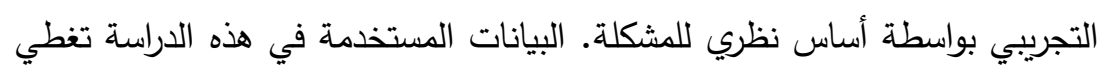

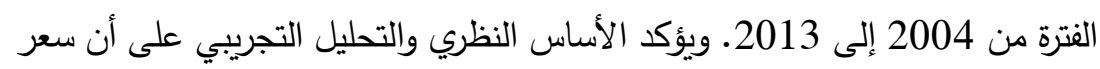
الصرف عامل جوهري في التأثير على التبادل التجاري الثنائي بين بولندا وشركائها

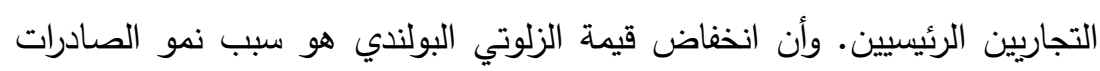

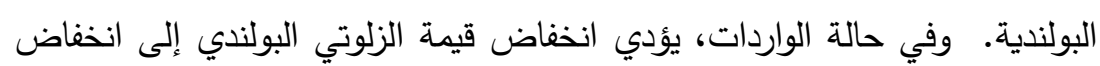

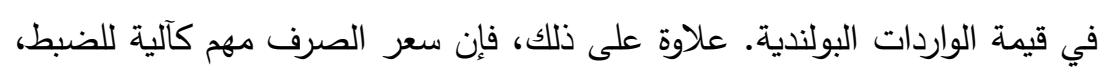


والتي بفضلها تمكن الاقتصاد البولندي من تجنب انخفاض كبير في الصادرات والناتج المحلي الإجمالي خلال فترة الأزمة المالية والاقتصادية الأخيرة.

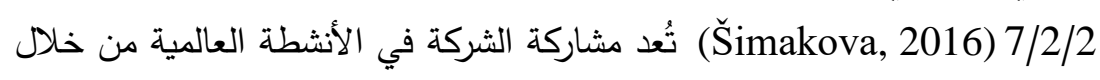
التجارة الدولية هي المصدر الرئيسي للتعرض لمخاطر صرف العملات الأجنبية. تثير

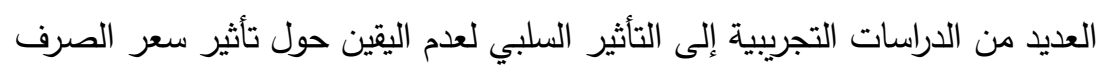

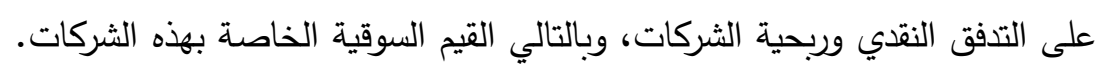
تظهر بعض الدراسات الاقتصاديات أن العائدات الأجنبية ترتبط ارتباطا إيجابيًا بالتعرض لمخاطر سعر الصرف وفي فترة قصيرة، ويؤثر انخفاض قيمة العملة سلبًا

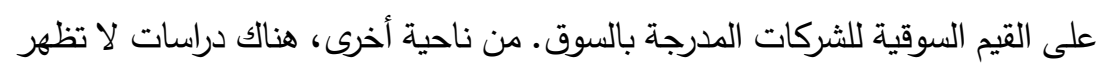

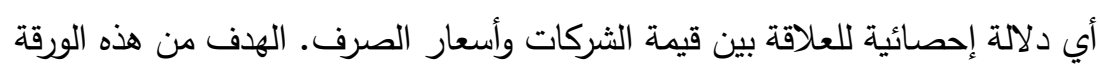
هو تقييم تأثير أسعار الصرف على قيمة الشركات المدرجة في البورصات في بلدان Visegrad $.2016: 2002$ أظهرت التقديرات للفترة بأكملها وجود علاقة سلبية بين سعر الصرف وقيمة أسهم

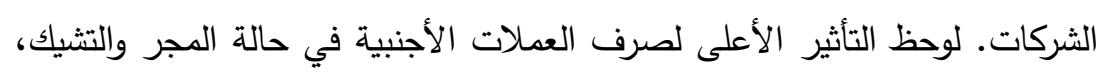
جميع الأسواق أظهرت انخفاض في معدل التعرض لمخاطر سعر الصرف مع الوقت.

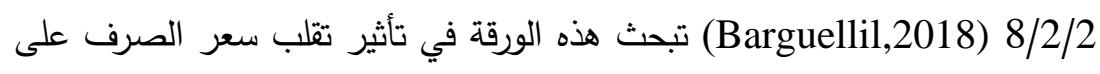
النمو الاقتصادي. تم إجراء تحقيق تجريبي يعتمد على عينة من 45 دولة نامية

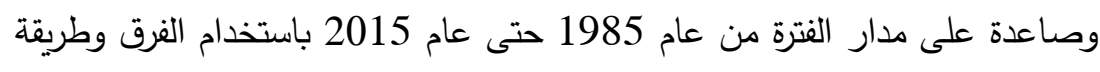

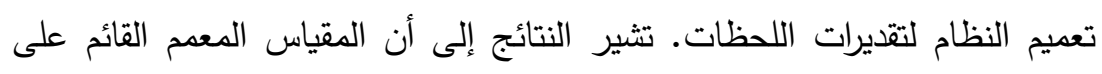
التغاير المشروط القائم على تقلبات سعر الصرف الاسمية والحقيقية له تأثير سلبي

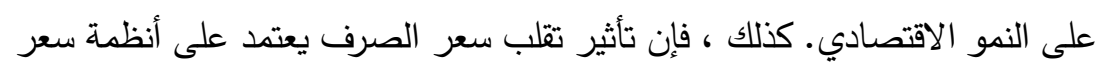

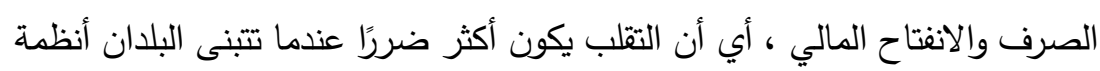

$$
\text { مرنة لسعر الصرف والانفتاح المالي. }
$$




\section{3/ الفجوة البحثية:}

من الملاحظ على كل الأبحاث العربية أنها تتاولت تأثير سعر الصرف في مجالات

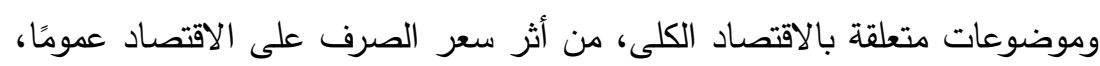

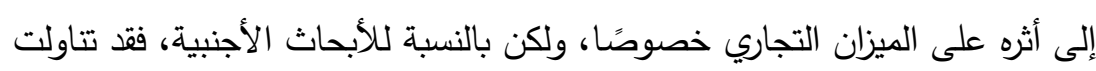

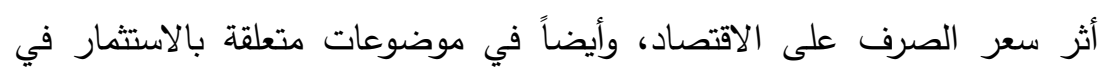

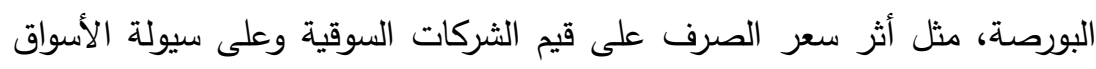

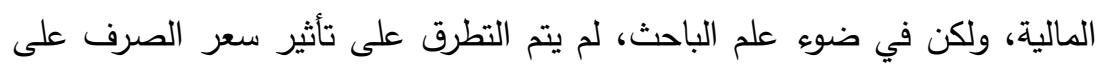

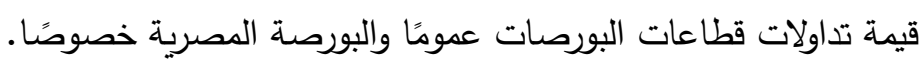

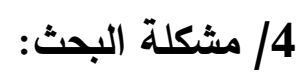
كيف تؤثر أسعار الصرف على قيم تداولات قطاعات البورصة المصرية المختلفة؟

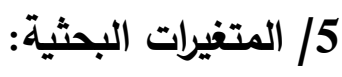
يتمثل المتغير المستقل في سعر الصرف. والمتغيرات التابعة تتمثل في قيم تداولات قطاعات البورصة المصرية المختلفة وهي (الاتصالات، الخدمات المالية، العقارات، السياحة والترفيه، التشييد ومواد البناء، لتاتهات

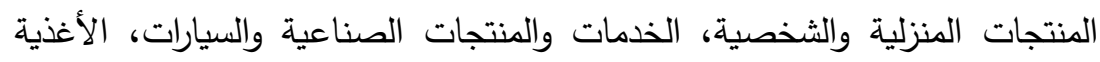
والمشروبات، البنوك، الرعاية الصحية والأغذية، الموارد الأساسية، والكيماويات).

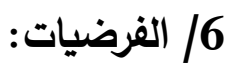
1/6 لا يوجد تأثير ذو دلالة إحصائية لسعر الصرف على قيم تداولات قطاع الاتصالات بالبورصة المصرية. 2/6 لا يوجد تأثير ذو دلالة إحصائية لسعر الصرف على قلى قيم تداولات قطاع الخدمات المالية (باستثاء البنوك) بالبورصة المصرية. 
3/6 لا يوجد تأثير ذو دلالة إحصائية لسعر الصرف على قيم تداولات قطاع العقارات بالبورصة المصرية.

4/6 لا يوجد تأثير ذو دلالة إحصائية لسعر الصرف على قيم تداولات قطاع السياحة والترفيه

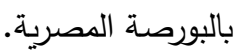

5/6 لا يوجد تأثير ذو دلالة إحصائية لسعر الصرف على قيم تداولات قطاع التثييد ومواد البناء بالبورصة المصرية. 6/6 لا يوجد تأثير ذو دلالة إحصائية لسعر الصرف على قيم تداولات قطاع المنتجات المنزلية والثخصية بالبورصة المصرية. 7/6 لا يوجد تأثير ذو دلالة إحصائية لسعر الصرف على قيم تداولات قطاع الخدمات والمنتجات الصناعية والسيارات بالبورصة المصرية. 8/6 لا يوجد تأثير ذو دلالة إحصائية لسعر الصرف ولئات بلى قيم تداولات قطاع الأغذية والمشروبات بالبورصة المصرية. 9/6 لا يوجد تأثير ذو دلالة إحصائية لسعر الصرف على قيم تداولات قطاع البنوك بالبورصة

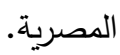
10/6 لا يوجد تأثير ذو دلالة إحصائية لسعر الصرف على قيم تداولات قطاع الرعاية الصحية

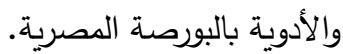
11/6 لا يوجد تأثير ذو دلالة إحصائية لسعر الصرف على قيم تداولات قطاع الموارد الأساسية

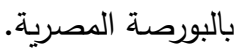
12/6 لا يوجد تأثير ذو دلالة إحصائية لسعر الصرف على قيم تداولات قطاع الكيماويات بالبورصة المصرية.

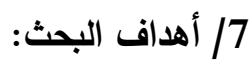

1/7 دراسة أثر سعر الصرف على قيم تداولات قطاعات البورصة المصرية المختلفة.

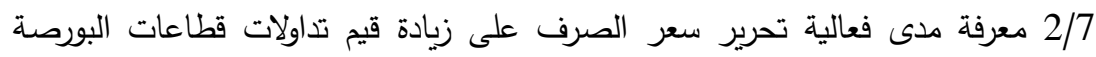
المصرية المختلفة. 3/7 معرفة أي من هذه القطاعات هو الأكثر تأثراً بسعر الصرف. 
1/8 الأهمية العلمية:

1/1/8 محاولة إثراء مكتبة الأبحاث العربية بدراسات تتتاول تأثير واحدة من أهم المتغيرات الاقتصاديات على قيم تداولات قطاعات البورصة المختلفة.

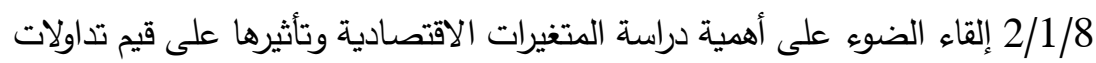
قطاعات البورصة المختلفة.

2/8 الأهمية العملية:

1/2/8 دعم وترشيد عملية اتخاذ القرار الاستثماري بالبورصة المصرية من قبل المستثمر سواء المستثمر الفرد أو المؤسي وذلك من خلال توضيد التيح العلاقة بين قيم التداول لكل قطاع من قطاعات البورصة وسعر الصرف.

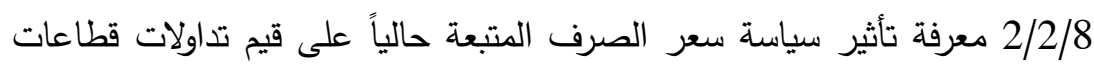
البورصة المختلفة. 3/2/8 توجيه المستثر نحو التعرف على القطاعات الأكثر تأثرًا بأي تغير في سعر الصرف مستقبليًا.

\section{9/9 منهج الدارسة:}

اتبع الباحث المنهج التحليلي الوصفي للتعرف على الجانب النظري من سعر الصرف وقطاعات البورصة وأحجام التداول، أما الجانب التطبيقي فقد قام الباحث باستخدام المنهج الاحصائي القياسي لتحليل أثر سعر الصرف على أحجام تداول قطاعات

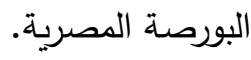


سعر الصرف ينعكس من خلاله وضع الدولة في مجال التجارة الخارجية مع باقي

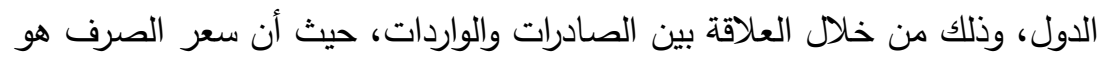

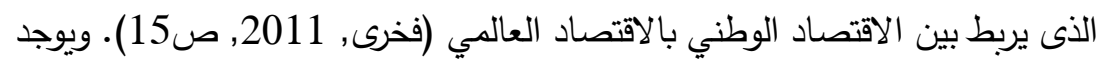

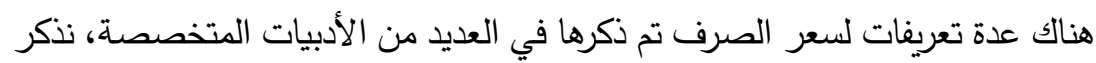
منها:

هو السعر الذى تتم به عملية بيع أو شراء عملة معينة مقابل وحدة واحدة من عملة أخرى. - من. أو هو المعدل الذى يتم على أساسه عملية تبادل عملة بعملة أخرى أو أحما

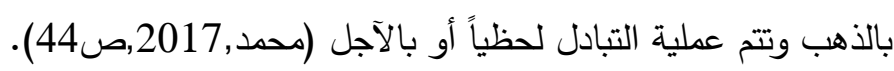
أو هو عدد الوحدات الواجب أن تدفع من عملة معينة في مقابل وحدة من عملة أخرى (قانة, 2009, صو عند الوحات الواجب. أو هو ثن عملة دولة ما مقومة في شكل عملة دولة أخرى

$$
\text { (عوض الله,2008, ص444). }
$$
أو هو السعر الذى يتم من خلاله مبادلة سلعة بأخرى (السربيتى,2009,

\section{2/10 أثكال سعر الصرف:}

سعر الصرف الأسمى: وهو مقياس لقيمة عملة بلد ما والتي يمكن أن يتم استبدالها بقيمة عملة بلد آخر .

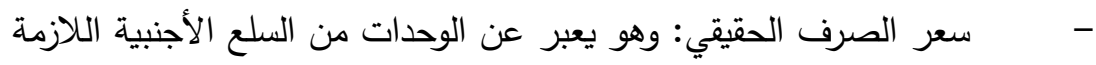

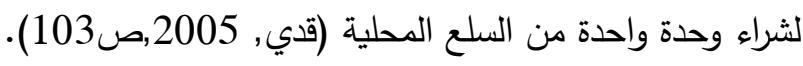

$$
\begin{aligned}
& \text { ويتم حسابه كما يلي: }
\end{aligned}
$$


إذا افترضنا أن مستوى الأسعار لبلد ما يتم التعبير عنه بالرمز p وفي البلد الآخر

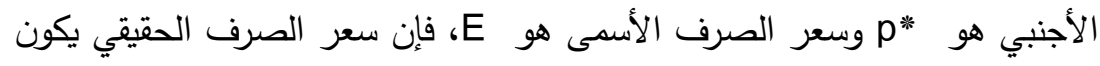
$\mathrm{e}=\mathrm{Ep} * / \mathrm{p}$

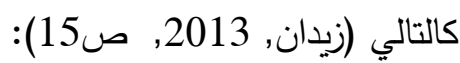
وكلما قل الفرق بين سعر الصرف الأسمى وسعر الصرف الحقيقي، دل ذلك على

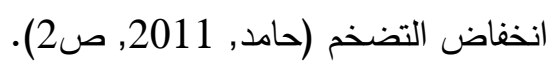

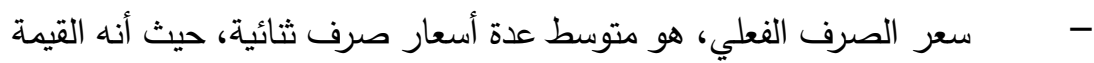
الحقيقية للعملة المحلية بالنسبة للعملة الخارجية، أي قدرة العملة المحلية الثرائية بالنسبة للدولة الأجنبية. - - - معر الصرف التوازني، هو سعر الصرف المتسق مع حالة توازن الاقتصاد

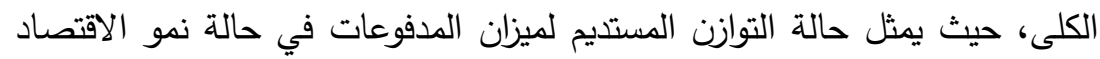

$$
\text { بمعدل نمو طبيعي (درقال, 2011, صلك)، }
$$

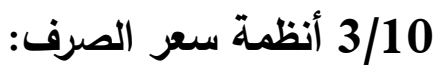

نظام سعر الصرف هو مجموعة القواعد المؤسسية التي تبين بدقة كيفية تحديد أسعار

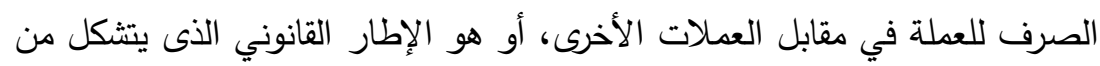

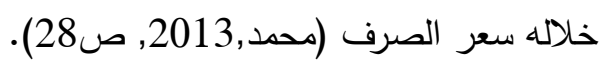
1/3/10 نظام الصرف الثابت: حيث يتم فية ربط سعر صرف العملة المحلية بعملة أخرى ذات ثقل دولي وتتميز

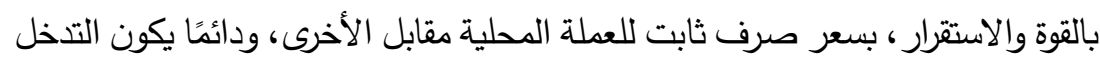
من السلطات المختصة المحلية في سوق الصرف يستهدف المحافظة على استقرار قيمة العملة المحلية مقابل العملة الأخرى، ويولد هذا النظام ثقة من قبل المستثمرين في عملة هذا البلد ويشجع حركة التجارة الخارجية (Madura, 2006, p87) . 
2/3/10 نظام الصرف المعوّم: يتم فيه تحديد سعر الصرف بناء على قوى الطلب

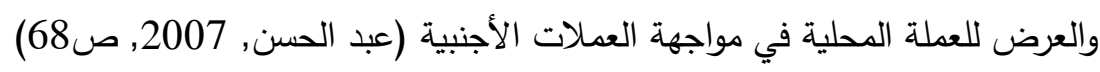
، ويمكن تقسيمه لنوعين: 1/2/3/10 نظام التعويم الحر: في هذا النظام، تتحدد سعر العملة بناء على قوى الطلب والعرض، صعودًا وهبوطًا، أي تتكيف العملة في هذا النظام مع الحالة الاقتصادية للبلد.

1/2/3/10 نظام التعويم المدار : تتدخل في هذا النوع من أنظمة الصرف السلطات

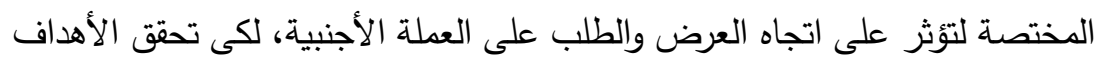

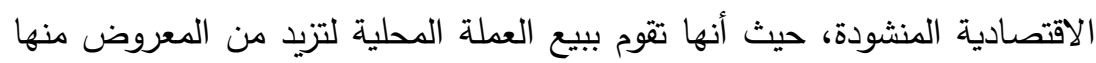
لتقوم بغرض خفض قيمتها، لكى تخفض أسعار صادرتها وتزبد منها، مما يؤدى لتتشيط الاقتصاد، أو تقوم بشراء العملة، لكى تزيد من قيمتها، و بالتالي تحد من عمليات

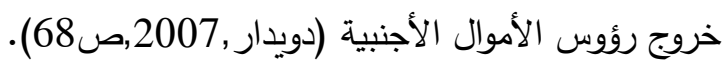

4/10 العوامل المؤثرة في سعر الصرف(Mishkin, 2009, p441 ): 1/4/10 حجم الإنتاج: البلدان الأكثر إنتاجية بالمقارنة بالبلدان الأخرى، ترتفع قيمة

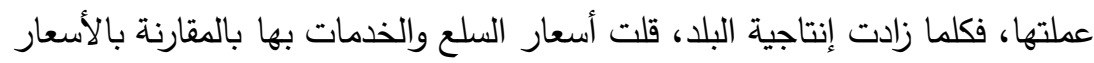

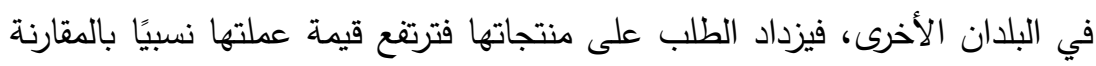
بعملات البلدان الأخرى. 2/4/10 الميزان التجاري: كلما زادت صادرات البلد بالمقارنة بوارداتها، ترتفع قيمة عملتها المحلية مقابل عملات شركائها التجاريين، و كلما زادت واردات البلد بالمقارنة بصادراتها، تتخفض قيمة عملتها مقابل عملات شركائها التجاريين. 3/4/10 الجمارك والضرائب على الواردات: التعريفات الجمركية وكذلك الضرائب التي علي تقوم الدول بفرضها على الواردات، تقوم بالتأثير على حجم الواردات التي تدخل للدولة التهرئ وبالتالي يتأثر العرض والطلب على العملات الأجنبية في مقابل العملة المحلية، وأيضاً 
يزيد الطلب على المنتجات المتثابهة المحلية الصنع، مما يؤدى لزيادة قوة العملة المحلية في مقابل العملات الأجنبية.

4/4/10 مستوى الأسعار نسبيًا: في حالة زيادة الأسعار للسلع والخدمات المحلية

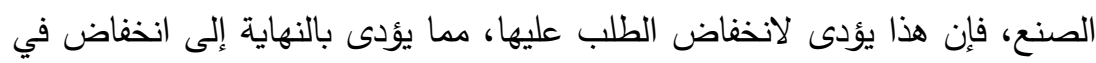
قيمة العملة المحلية. وهناك عوامل أخرى أيضاً تقوم بالتأثير في سعر الصرف مثل (عباس وعبدالله, 2015, ص 153:

سعر الفائدة: تؤثر على سعر الصرف ولكن بطريقة غير مباشرة، حيث أنه عند إتباع سياسة انكماشية برفع سعر الفائدة، يؤدى ذلك إلى الإحجام عن الاستثمار مما يؤدى لانخفاض في معدل النمو الاقتصادي مما يؤثر على قيمة العملة المحلية بالانخفاض، أما لو تم إتباع سياسة توسعية بخفض أسعار الفائدة، يؤدى ذلك لتتشيط الاستثمارات وزيادة معدل النمو الاقتصادي وبالتالي زيادة قيمة العملة المحلية. - - - - مالديون الخارجية: في حالات التعثر خصوصًا، تؤدى عمليات إعادة الجدولة لفرض معدلات فائدة أعلى، مما يكبل الاقتصاد عمومًا وسعر الصرف للعملة المحلية الصدية خصوصًا.

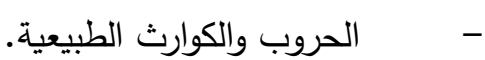

\section{5/10 النظربات المفسرة لسعر الصرف:}

1/5/10 نظرية تعادل القوة الثرائية: حاول الاقتصادي السويدي جوستاف كاسل أن

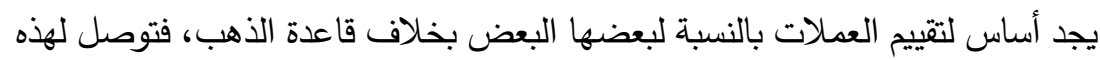
النظرية، حيث أن الفكرة فيها أن سعر التعادل بين كل عملتين يتم تحديده في حالة تعادل القوة الشرائية لكل عملة في سوقها المحلى مع قوتها في سوق الدولة الأخرى،

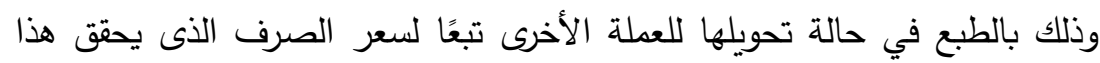
التعادل. 


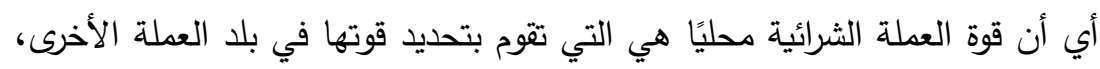
أي أن مستويات الأسعار محليًا هي التي تقوم بتحديد سعر الصرف (موسى وآخرون,

. 2012,ص 1672

2/5/10 نظرية تعادل أسعار الفائدة: خلاصة هذه النظرية تتمثل في أن قيمة عملة

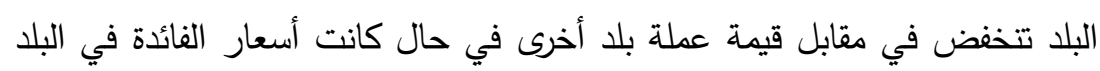
الأخرى أكبر من أسعار الفائدة في البلد الأولى، حيث عقيث أن أسعار الفائدة في البلدين

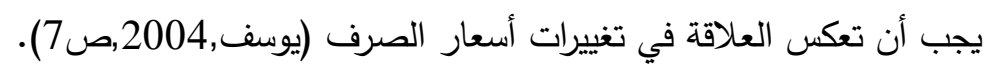

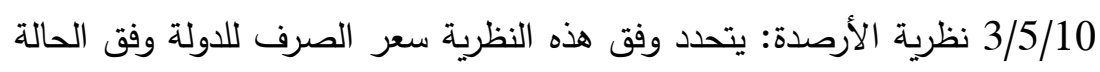

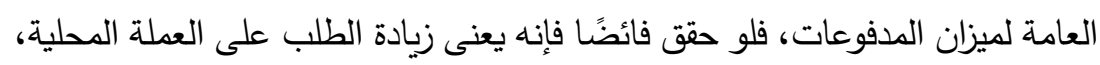
وبالتالي ترتفع قيمتها في مقابل العملات الأخرى، أما إذا حقق عجزًا فإنه يعنى زيادة في الكميات المعروضة من عملة الدولة وبالتالي يؤدى لانخفاض قيماتهات فيمتها. 4/5/10 وهناك كذلك نظريات أخرى مثل نموذج ماندل - فلمنج والنظرية الإنتاجية والنظرية النقدية ونموذج ميزان محفظة الأوراق المالية، وكلها تقوم بتفسير التغيرات في ماني

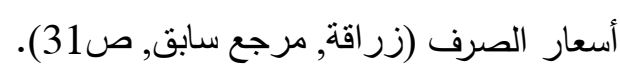
6/10 قطاعات البورصة: هي المجالات الرئيسية للاستثمار في النثاط الاقتصادي في الدولة.

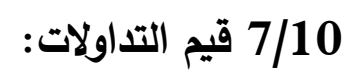
هي مجموع أحجام التداول (أي مجموع أعداد الأوراق المالية التي تم تتفيذ عمليات البيع والثراء عليها)، مضروبًا في أسعار التتفيذ للعمليات. 


$$
\begin{aligned}
& \text { 11/ تصميم الإطار التنفيذي للبحث: } \\
& \text { 1/11 محددات مجتمع البحث: }
\end{aligned}
$$

قيم تداولات قطاعات البورصة المصرية الاثني عشرة المعلن عنها في تقارير

البورصة المصرية الثهرية المنشورة في الفترة من يناير 2015 إلى فبراير 2019 لتمثل اثثى عشره سلسله زمنيه لكل قطاع، بعدد 50 مفردة لكل سلسلة.

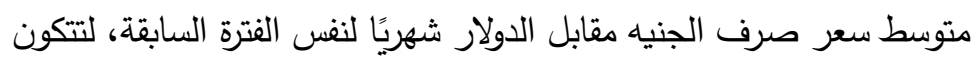

سلسله زمنية بعدد 50 مفردة لسعر صرف الجنيه . مان.

$$
\text { 2/11 طرق جمع البيانات: }
$$

المسح المستندي لتقارير البورصة المصرية المنشورة على شبكة الإنترنت، وكذلك

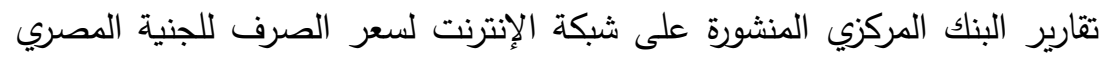
مقابل الدولار . 3/11 مصادر البيانات:

$$
\text { موقع البورصة المصرية على الإنترنت: }
$$

http://www.egx.com.eg/ar/homepage.aspx

$$
\text { موقع البنك المركزي على الإنترنت: }
$$

https://www.cbe.org.eg/ar/Pages/default.aspx

$$
\text { 4/11 أساليب التحليل الاحصائي المستخدمة: }
$$

،Pearson's Correlation Coefficient 1/4/11 معامل ارتباط بيرسون 1/4/

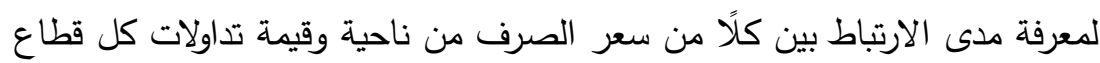
من قطاعات البورصة من ناحية أخرى. 2/4/11 اختبار الموثوقية Cronbach's Alpha، لمعرفة مدى اتساق وتجانس نداحس المتغيرات فيما بينها. 
3/4/11 اختبار الاستقلال، كا2hi-square، وكذلك اختبار ويكوكس لمعرفة مدى وجود

استقلال بين المتغيرات من عدمه.

4/4/11 اختبار ثبات السلاسل الزمنية للمتغيرات البحثية، Dickey-Fuller، لاختبار

استقرار السلاسل الزمنية للمتغيرات البحثية.

5/4/11 تحليل التباين، ANOVA ، لمعرفة مدى وجود اختلافات بين متوسطات السلاسل

الزمنية للمتغيرات التابعة ومتوسط السلسلة الزمنية للمتغير المستقل.

6/4/11 تحليل الانحدار، Regression Analysis، لاختبار الفرضيات الإحصائية

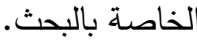

12

1/12 بعض المقاييس الإحصائية لمتوسط سعر الصرف الثهري وقيمة التداولات

الشهريـة لقطاعات البورصة :

Descriptive Statistics

\begin{tabular}{|c|c|c|c|c|}
\hline القطاع & $\begin{array}{l}\text { Mean } \\
\text { الوسط }\end{array}$ & $\begin{array}{l}\text { Median } \\
\text { الوسيط }\end{array}$ & $\begin{array}{l}\text { Std. Deviation } \\
\text { الانحراف المعياري }\end{array}$ & $\begin{array}{c}\text { Skewness } \\
\text { م. الالتواء }\end{array}$ \\
\hline اتصالات & 2257.7080 & 1881.9000 & 1335.56345 & 2.132 \\
\hline مالية & 3676.1240 & 3269.2000 & 1884.04380 & 1.204 \\
\hline عقارات & 3608.0480 & 3016.4500 & 1917.96233 & 1.941 \\
\hline سياحة & 622.0840 & 475.4000 & 450.84256 & 1.733 \\
\hline تثييد & 791.0460 & 513.1000 & 1771.81455 & 6.807 \\
\hline منزلية & 1012.6060 & 770.2500 & 872.20768 & 2.400 \\
\hline سيارات & 1010.6840 & 811.6000 & 754.99606 & 1.662 \\
\hline أغذية & 993.9080 & 727.5500 & 855.01618 & 2.857 \\
\hline بنوك & 2138.6940 & 2013.4500 & 796.56781 & 1.280 \\
\hline صحية & 339.4620 & 185.6000 & 447.05916 & 3.700 \\
\hline أساسية & 800.7320 & 596.8000 & 601.09495 & 1.046 \\
\hline كيمياويات & 540.5460 & 393.9500 & 480.77581 & 0.869 \\
\hline سعر الصرف & 13.5691 & 17.6513 & 4.89406 & -0.254 \\
\hline
\end{tabular}


نلاحظ أن قيم تداولات جميع القطاعات ملتوية التواءًا موجبًا (المتوسط > الوسيط)

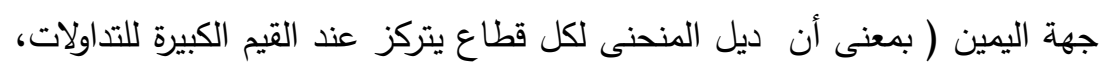
و أن قمة المنحنى تتركز حول القيم الصغيرة لتداولات البورصة).

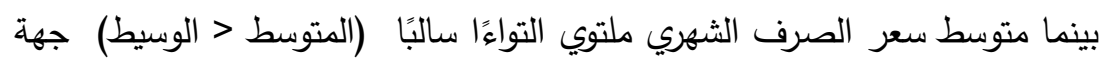
اليسار ( بمعنى أن ذيل المنحنى لبيانات سعر الصرف يتركز عند القيم الصغيرة لسعر الصرف، وأن قمة المنحنى تتركز حول القيم الكبيرة لسعر الصرف).

2/12 معامل ارتباط بيرسون (Pearson's Correlation Coefficient):

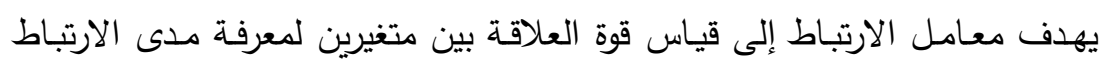

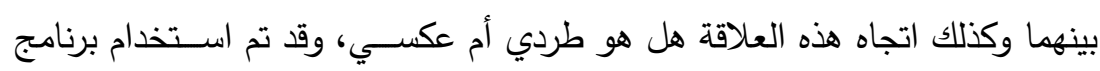
لمعرفة قوة واتجاه العلاقة وذلك بحساب معامل ارتباط بيرسون، كما تم القيام بالاستعانة بالبرنامج لمعرفة قيمة (p-value) لمعرفة مدى معنوية هذا الارتباط وهل

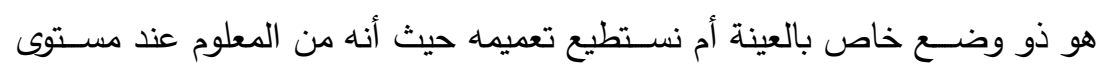

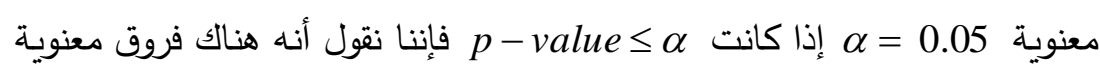

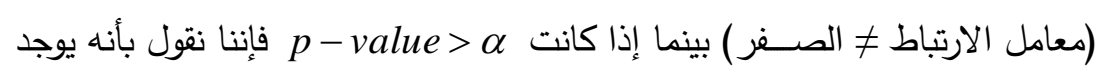

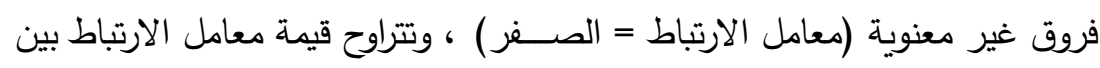
. (1 1 1 )

وكلما قربت قيمة معامل الارتباط من الواحد الصـحيح كلما كان الارتباط قويًا، بينما

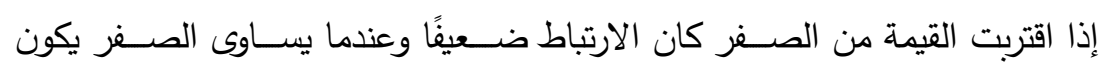
الارتباط منعدمًا.

وقد حصلنا على النتائج التالية لدراسـة قوة الارتباط بين سعر الصـرف وقيمة التداول في قطاعات البورصة : 


\begin{tabular}{|c|c|c|c|}
\hline القطاع & معامل ارتباط بيرسون & $\mathrm{p}$-value & نوع الارتباط \\
\hline اتصالات & 0.40 & 0.00 & معنوي \\
\hline مالية & 0.67 & 0.00 & معنوي \\
\hline عقارات & 0.51 & 0.00 & معنوي \\
\hline سياحة & 0.587 & 0.00 & معنوي \\
\hline تشييد & $0.09-$ & 0.51 & غير معنوى \\
\hline منزلية & 0.55 & 0.00 & معنوي \\
\hline سيارات & 0.67 & 0.00 & معنوي \\
\hline أغذية & 0.33 & 0.01 & معنوي \\
\hline بنوك & 0.48 & 0.00 & معنوي \\
\hline صحية & 0.40 & 0.00 & معنوي \\
\hline أساسية & 0.66 & 0.00 & معنوي \\
\hline كيمياويات & 0.75 & 0.00 & معنوي \\
\hline
\end{tabular}

ومعنى ذلك أن هناك ارتباط معنوي بين متوسط سعر الصرف الثهري وجميع

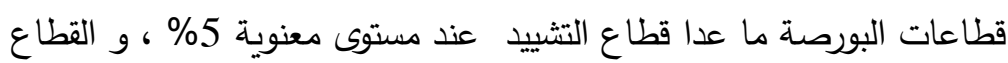
الغذائي عند مستوى معنوية 1\%. وسوف نلاحظ تلك النتيجة فيما بعد عند القيام

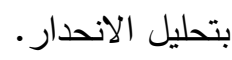


3/12 اختبار مدى تجانس المتغيرات مع بعضـها أو ما يســى باختبار الموثوقية

Reliability

وهنا سوف يتم حساب مقياس يسمى Cronbach's Alpha وهذا المقياس كلما

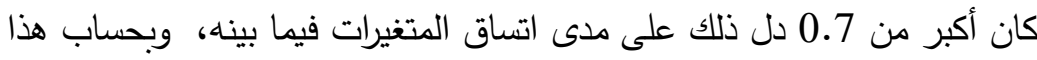

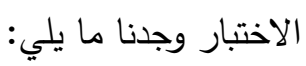

Reliability Statistics

\begin{tabular}{|c|c|}
\hline Cronbach's Alpha & N of variables \\
\hline 0.838 & 13 \\
\hline
\end{tabular}

معنى ذلك أن هناك اتساق وتجانس كبير بين جميع المتغيرات الثلاثة عشر ( سعر الصرف، وقطاعات البورصة الاثتي عشر).

4/12 اختبار الاستقلال (Cross Tabulation) كاء2:

فرضية العدم للاختبار : أن المتغيرات مستقلة.

الفرضية البديلة للاختبار : أن المتغيرات غير مستقلة.

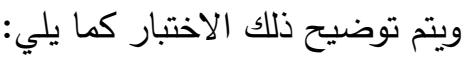

Chi-Square Tests

\begin{tabular}{|l|c|c|}
\hline & $\begin{array}{c}\text { Statistic } \\
\text { اختبار من طرفين }\end{array}$ \\
\hline Pearson Chi-Square & 2050.000 & 0.257 \\
Likelihood Ratio & 363.476 & 1.000 \\
Linear-by-Linear Association & 22.351 & .000 \\
\hline
\end{tabular}

P-value ) Pearson Chi-Square =2050 ولدراسة استقلال المتغيرات وجدنا أن قيمة

$$
0.257 \text { = ) بما يعني أنه يوجد استقلال بين المتغيرات. }
$$

كنلك لتأكيد ذلك نستخلم Wilcoxon Signed Ranks Test هذا الاختبار يؤكد أنه لا يوجد اعتمادية ( يوجد استقلالية بين المتغيرات).

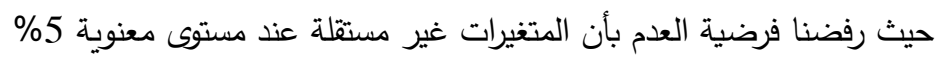
لسعر الصرف من ناحية وقيم التداول لكل قطاع من ناحية أخرى . 


\begin{tabular}{|c|c|c|c|c|c|c|c|c|c|c|c|c|}
\hline & |تصالات & مالية & |عقارات & سياحة | سياد & تشييد & |منزلية | منية & سيارات & أغذية & بنوك & صحية & |أساسية & كيماويات \\
\hline $\begin{array}{c}Z \\
-6.154\end{array}$ & & & & & & & & & & & & \\
\hline $\mathrm{P}$-value & .000 & .000 & .000 & .000 & .000 & .000 & .000 & .000 & .000 & .000 & .000 & .000 \\
\hline
\end{tabular}

Augmented Dickey- 5/12 كما يمكن اختبار ثبات السلسلة باستخدام

Fuller Test

يقوم اختبار ديكي - فولر (ADF) المعزز باختبار مدى استقرار السلاسل الزمنية

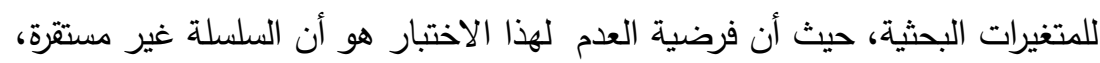

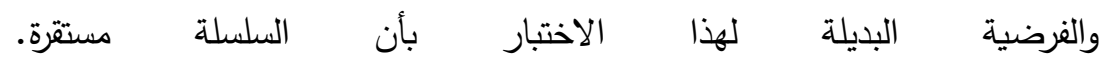
الإحصاء المعزز لـ Dickey-Fuller (ADF) ، المستخدمة في الاختبار رقم

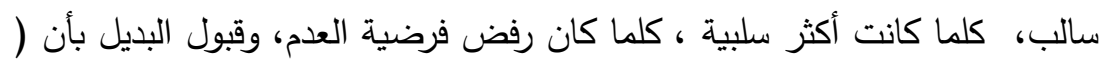
السلسلة مستقرة ) عند مستوى معين من المعنوية. Alternative ' P-value $=0.01$. Dickey-Fuller $=-4.4674$ hypothesis: Stationary.

$$
\text { حيث أن } 0.05 \text { value } 0.05
$$

لذلك فإن السلاسل الزمنية مستقرة عند مستوي معنوية 5\%٪. 6/12 تحليل التباين (ANOVA) وهنا نقوم بدراسة هل هناك اختلاف معنوي بين متوسطات سعر الصرف من ناحية وبين متوسطات قيم التداول في كل قطاع من قطاعات البورصة على حده عند

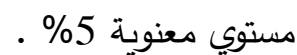
هنا في هذا الاختبار تكون فرضية العدم : لا يوجد اختلاف معنوي بين المتوسطات، بينما الفرضية البديل : يوجد اختلاف معنوي بين المتوسطات . وبإجراء الاختبار حصلنا على التالي : 
ANOVA

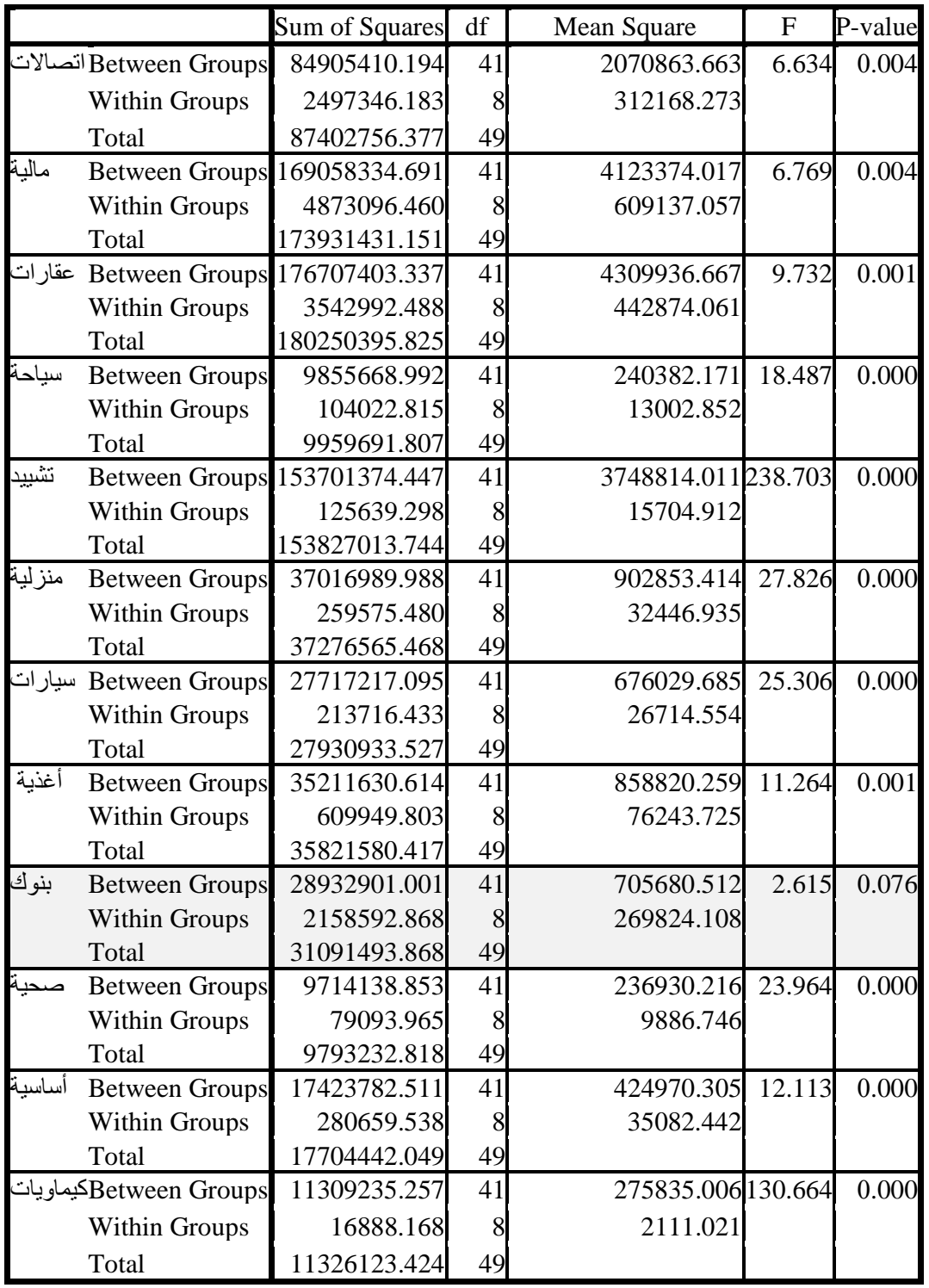


من الجدول السابق نلاحظ أن هناك اختلافا معنويًا ( 0.05 -value إحصائية بين متوسط سعر الصرف الثهري وبين قيمة التداولات لجميع قطاعات البورصة ما عدا قطاع البنوك ( 12 -value > 0.05 ).

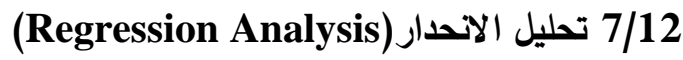

وهنا نقوم باختبار فرضيات البحث وهي هل هناك أثر معنوي لمتوسط سعر الصرف

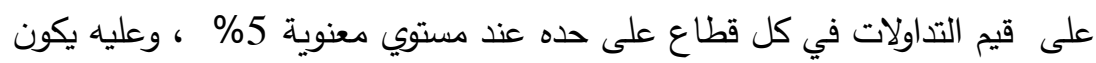
بشكل منفصل: فرضية العدم : لا يوجد تأثير معنوي لسعر الصرف على قيمة تداولات البورصة لكل قطاع على حده. الفرضية البديل : يوجد تأثير معنوي لسعر الصرف على قيمة تداولات البورصة لكل قطاع على حده. كما سنوضح أيضًا في كل حالة معادلة الانحدار الخاصة بها وكذلك قيمة كل من ف Adjusted-R-Square ، R-Square التداول في كل قطاع يمكن تقسيرها أو تعود إلى التغير في متوسط أسعار الصرف الثهرية فقط، أم أن هناك عوامل أخرى تؤثر في قيم التداول كما يلي:

\section{1/7/12 بخصوص العلاقة بين سعر الصرف وقطاع الاتصالات:} Model Summary

\begin{tabular}{|c|c|}
\hline R Square & Adjusted R Square \\
\hline 0.165 & 0.148 \\
\hline
\end{tabular}

من الجدول السابق نلاحظ أن التغيرات في قيم التداول الخاصة بقطاع الاتصالات

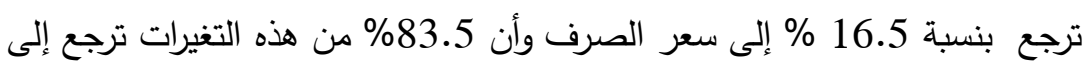
متغيرات أخرى. 
ANOVA

\begin{tabular}{|l|r|r|r|r|r|}
\hline Model & Sum of Squares & df & Mean Square & F & P-value \\
\hline Regression & 14449049.697 & 1 & 14449049.697 & 9.507 & 0.003 \\
Residual & 72953706.680 & 48 & 1519868.889 & & \\
Total & 87402756.377 & 49 & & & \\
\hline
\end{tabular}

من جدول تحليل الانحدار نلاحظ أن palue =0.003 أي أن هناك أثر معنوي لسعر الصرف على قيم التداول في قطاع الاتصالات بمستوى معنوية 5\%. لذلك فإننا نرفض فرضية العدم بأنه لا يوجد تأثير ذو دلالة إحصائية لسعر الصرف على قيم تداولات قطاع الاتصالات بالبورصة المصرية. ونقبل الفرضية البديلة بأنه يوجد تأثير ذو دلالة إحصائية لسعر الصرف على قيم تداولات قطاع الاتصالات بالبورصة المصرية. Coefficients

\begin{tabular}{|c|c|c|c|c|}
\hline \multirow{2}{*}{ Model } & \multicolumn{2}{|c|}{ Un-standardized Coefficients } & \multirow{2}{*}{} & \multirow{2}{*}{ P-value } \\
\cline { 2 - 3 } & B & Std. Error & $\mathrm{t}$ & 0.153 \\
\hline الثابn & 752.125 & 518.494 & 1.451 & 0.003 \\
\hline
\end{tabular}

ويمكن كتابة معادلة الانحدار المقدرة كما يلي: قيمة التداول في قطاع الاتصالات = 752.125 + 110.956 (سعر الصرف) 2/7/12 بخصوص العلاقة بين سعر الصرف وقطاع الخدمات المالية (باستثناء (لبنو)

Model Summary

\begin{tabular}{|c|c|}
\hline R Square & Adjusted R Square \\
\hline 0.456 & 0.445 \\
\hline
\end{tabular}

من الجدول السابق نلاحظ أن التغيرات في قيم التداول الخاصة بقطاع الخدمات المالية ترجع بنسبة 45.6 \% إلى سعر الصرف وأن 54.4\% من هذه التغيرات ترجع إلى متغيرات أخرى.

ANOVA

\begin{tabular}{|l|r|r|r|r|c|}
\hline Model & Sum of Squares & df & Mean Square & F & $\begin{array}{c}\text { P- } \\
\text { value }\end{array}$ \\
\hline Regression & 79338977.112 & 1 & 79338977.112 & 40.260 & 0.000 \\
Residual & 94592454.039 & 48 & 1970676.126 & & \\
Total & 173931431.151 & 49 & & & \\
\hline
\end{tabular}


من جدول تحليل الانحدار نلاحظ أن palue =0.000 أي أن هناك أثر معنوي لسعر

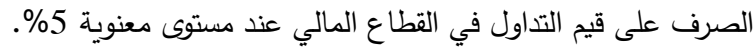

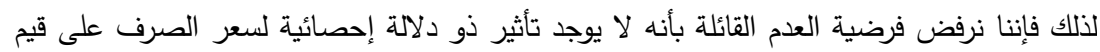
تداولات قطاع الخدمات المالية ( باستثاء البنوك) بالبورصة المصرية.

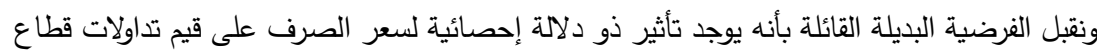
الذدمات المالية ( باستثاء البنوك) بالبورصة المصرية. Coefficients

\begin{tabular}{|c|c|c|c|c|}
\hline & & & & \\
\hline \multirow[b]{2}{*}{ Model } & \multicolumn{2}{|c|}{ Un-standardized Coefficients } & \multirow[b]{2}{*}{$\mathrm{t}$} & \multirow[b]{2}{*}{ P-value } \\
\hline & $\mathrm{B}$ & Std. Error & & \\
\hline الثابت & 148.125 & 590.402 & .251 & .803 \\
\hline ل الميل & 260.002 & 40.977 & 6.345 & .000 \\
\hline
\end{tabular}
ويمكن كتابة معادلة الانحدار المقدرة كما يلي: قيمة التاول في قطاع الخدمات المالية= 148.125 + 260.002 (سعر الصرف) 3/7/12 بخصوص العلاقة بين سعر الصرف وقطاع العقارات:

\section{Model Summary}

\begin{tabular}{|c|c|}
\hline R Square & Adjusted R Square \\
\hline 0.267 & 0.252 \\
\hline
\end{tabular}

من الجدول السابق نلاحظ أن التغيرات في قيم التداول الخاصة بقطاع العقارات ترجع بنسبة 26.7 \% إلى سعر الصرف وأن 73.3\% من هذه التغيرات ترجع إلى متغيرات أخرى.

ANOVA

\begin{tabular}{|l|r|r|r|r|r|}
\hline Model & Sum of Squares & df & Mean Square & F & P-value \\
\hline Regression & 48193396.761 & 1 & 48193396.761 & 17.517 & 0.000 \\
Residual & 132056999.064 & 48 & 2751187.481 & & \\
Total & 180250395.825 & 49 & & & \\
\hline
\end{tabular}


من جدول تحليل الانحدار نلاحظ أن 0.000 -value =0 أي أن هناك أثر

معنوي لسعر الصرف على قيم التداول في قطاع العقارات بمستوى معنوية 5. لذلك فإننا نرفض فرضية العدم القائلة بأنه لا يوجد تأثير ذو دلاعلة إعلة إحصائية لسعر الصرف على قيم تداولات قطاع العقارات بالبورصة المصرية.

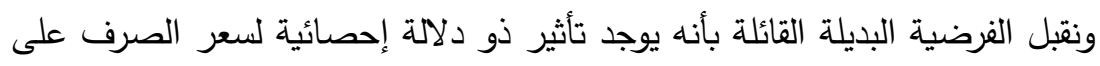
قيم تداولات قطاع العقارات بالبورصة المصرية.

Coefficients

\begin{tabular}{|l|r|r|r|r|}
\hline \multirow{2}{*}{ Model } & \multicolumn{2}{|c|}{ Un-standardized Coefficients } & & \\
\cline { 2 - 3 } & \multicolumn{1}{|c|}{ B } & Std. Error & \multicolumn{1}{c|}{ t } & P-value \\
\hline الثابn & 858.389 & 697.591 & 1.231 & 0.225 \\
الميn & 202.641 & 48.416 & 4.185 & 0.000 \\
\hline
\end{tabular}

ويمكن كتابة معادلة الانحدار المقدرة كما يلي:

قيمة التداول في قطاع العقارات = 858.389+ 202.641 (سعر الصرف)

4/7/12 بخصوص العلاقة بين سعر الصرف وقطاع السياحة: Model Summary

\begin{tabular}{|c|c|}
\hline R Square & Adjusted R Square \\
\hline 0.345 & 0.331 \\
\hline
\end{tabular}

من الجدول السابق نلاحظ أن التغيرات في قيم التداول الخاصة بقطاع السياحة ترجع بنسبة 34,5 \% إلى سعر الصرف وأن 64,5\% من هذه التغيرات ترجع إلى متغيرات أخرى.

ANOVA

\begin{tabular}{|c|c|c|c|c|c|c|}
\hline Model & $\begin{array}{l}\text { Sum of } \\
\text { Squares }\end{array}$ & $\mathrm{df}$ & & $\begin{array}{l}\text { Mean } \\
\text { Square }\end{array}$ & $\mathrm{F}$ & $\begin{array}{c}\mathrm{P}- \\
\text { value }\end{array}$ \\
\hline Regression & 3432929.262 & & & 3432929.262 & 25.247 & 0.000 \\
\hline Residual & 6526762.545 & & 48 & 135974.220 & & \\
\hline Total & 9959691.807 & & 4 & & & \\
\hline
\end{tabular}


من جدول تحليل الانحدار نلاحظ أن 0.000 -value =0 أي أن هناك أثر

معنوي لسعر الصرف على قيم التداول في قطاع السياحة بمستوى معنوية 5.

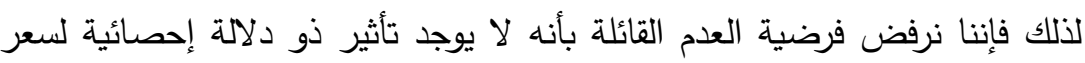
الصرف على قيم تداولات قطاع السياحة بالبورصة المصرية.

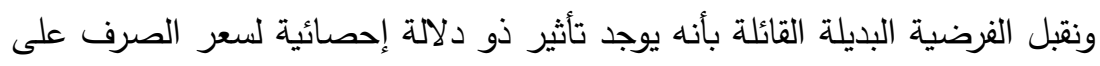
قيم تداولات قطاع السياحة بالبورصة المصرية.

Coefficients

\begin{tabular}{|l|r|r|r|r|}
\hline \multirow{2}{*}{ Model } & \multicolumn{2}{|c|}{ Un-standardized Coefficients } & & \\
\cline { 2 - 3 } & \multicolumn{1}{|c|}{ B } & Std. Error & \multicolumn{1}{c|}{ t } & P-value \\
\hline الثابry & -111.783 & 155.085 & -0.721 & 0.475 \\
الميل & 54.084 & 10.764 & 5.025 & 0.000 \\
\hline
\end{tabular}
ويمكن كتابة معادلة الانحدار المقدرة كما يلي:

قيمة التداول في قطاع السياحة =- 111.783 + 54.084 (سعر الصرف) كمابه 5/7/12 بخصوص العلاقة بين سعر الصرف وقطاع التشييد ومواد البناء: Model Summary

\begin{tabular}{|c|c|}
\hline R Square & Adjusted R Square \\
\hline 0.009 & 0.012 \\
\hline
\end{tabular}
ANOVA

\begin{tabular}{|c|r|r|r|r|c|}
\hline Model & Sum of Squares & df & Mean Square & F & $\begin{array}{c}\text { P- } \\
\text { value }\end{array}$ \\
\hline Regression & 1393849.698 & 1 & 1393849.698 & 0.439 & 0.511 \\
Residual & 152433164.046 & 48 & 3175690.918 & & \\
Total & 153827013.744 & 49 & & & \\
\hline
\end{tabular}


من جدول تحليل الانحدار نلاحظ أن palue =0.511 أي أنه لا يوجد أثر معنوي لسعر الصرف على قيم التداول في قطاع التثييد بمستوى معنوية 5\%. لذلك فإننا نقبل فرضية العدم القائلة بأنه لا يوجد تأثير ذو دلالة إحصائية لسعر الصرف على على فلى قيم تداولات قطاع التشييد بالبورصة المصرية. ونرفض الفرضية البديلة القائلة بأنه يوجد تأثير ذو دلالة إحصائية لسعر الصرف علية على قيم تداولات قطاع التثييد بالبورصة المصرية.

\section{Coefficients}

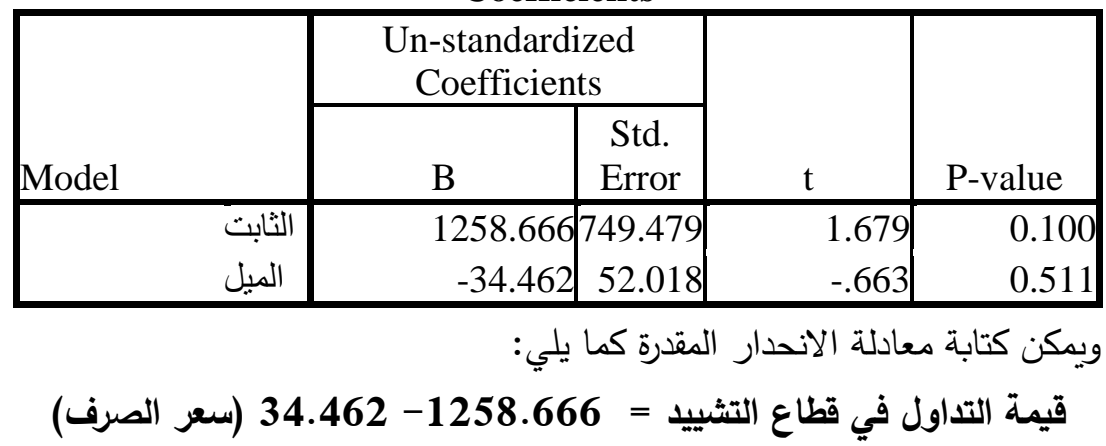

6/7/12 بخوص العلاقة بين سعر الصرف وقطاع المنتجات المنزلية والثخصية:

\section{Model Summary}

\begin{tabular}{|c|c|}
\hline R Square & Adjusted R Square \\
\hline 0.304 & 0.289 \\
\hline
\end{tabular}

\begin{tabular}{|r|r|r|r|c|c|}
\hline \multicolumn{7}{|c|}{ Model } & & Sum of Squares & df & Mean Square & F & $\begin{array}{c}\text { P- } \\
\text { value }\end{array}$ \\
\hline Regression & 11326587.699 & 1 & 11326587.699 & 20.951 & 0.000 \\
Residual & 25949977.769 & 48 & 540624.537 & & \\
Total & 37276565.468 & 49 & & & \\
\hline
\end{tabular}


من جدول تحليل الانحدار نلاحظ أن palue =0.000 أي أنه يوجد أثر معنوي لسعر الصرف على قيم التداول في قطاع المنتجات المنزلية والثخصية بمستوى معنوية 5\% لذلك فإننا نرفض فرضية العدم القائلة بأنه لا يوجد تأثير ذو دلالة إحصائية لسعر الصرف على على قيم تداولات قطاع المنتجات المنزلية والثخصية بالبورصة المصرية. ونقبل الفرضية البديلة القائلة بأنه يوجد تأثير ذو دلالة إحصائية لسعر الصرف على بلى قيم تداولات قطاع

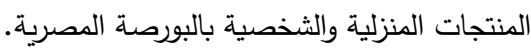

\section{Coefficients}

\begin{tabular}{|c|c|c|c|c|}
\hline \multirow[b]{2}{*}{ Model } & \multicolumn{2}{|c|}{$\begin{array}{l}\text { Un-standardized } \\
\text { Coefficients }\end{array}$} & \multirow[b]{2}{*}{$\mathrm{t}$} & \multirow{2}{*}{$\begin{array}{c}\mathrm{P}- \\
\text { value }\end{array}$} \\
\hline & B & Std. Error & & \\
\hline الثابت & -320.408 & 309.235 & -1.036 & .305 \\
\hline الميل & 98.239 & 21.463 & 4.577 & .000 \\
\hline
\end{tabular}

ويمكن كتابة معادلة الانحدار المقدرة كما يلي:

قيمة التداول في قطاع المنتجات المنزلية والشخصية= - 320.408 +

$$
98.239
$$

\section{7/7/12 بخصوص العلاقة بين سعر الصرف وقطاع الخدمات والمنتجات}

الصناعية والسيارات:

\section{Model Summary}

\begin{tabular}{|c|c|}
\hline R Square & Adjusted R Square \\
\hline 0.459 & 0.447 \\
\hline
\end{tabular}

من الجدول السابق نلاحظ أن التغيرات في قيم التداول الخاصة بقطاع الخدمات والمنتجات الصناعية

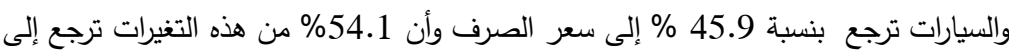
متغيرات أخرى.

ANOVA

\begin{tabular}{|l|r|r|r|r|r|}
\hline Model & \multicolumn{1}{|c|}{ Sum of Squares } & \multicolumn{1}{c|}{ df } & Mean Square & \multicolumn{1}{c|}{ F } & P-value \\
\hline Regression & 12809528.664 & 1 & 12809528.664 & 40.661 & 0.000 \\
Residual & 15121404.863 & 48 & 315029.268 & & \\
Total & 27930933.527 & 49 & & & \\
\hline
\end{tabular}


من جدول تحليل الانحدار نلاحظ أن palue=0.000 أي أنه يوجد أثر معنوي لسعر

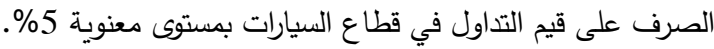
لذلك فإننا نرفض فرضية العدم القائلة بأنه لا يوجد تأثير ذو دلالة إحصائية لسعر الصرف على قيليم تاولات قطاع الخدمات والمنتجات الصناعية والسيارات بالبورصة المصرية.

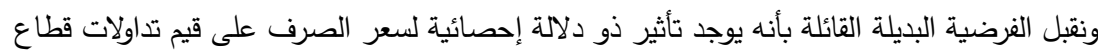
الخدمات والمنتجات الصناعية والسيارات بالبورصة المصرية. Coefficients

\begin{tabular}{|c|c|c|c|c|c|}
\hline \multirow[b]{2}{*}{ Model } & Un-standardi & $\mathrm{d}$ Coefficients & \begin{tabular}{|c} 
Standardize \\
$\mathrm{d}$ \\
Coefficient \\
$\mathrm{s}$ \\
\end{tabular} & \multirow[b]{2}{*}{$\mathrm{t}$} & \multirow[b]{2}{*}{ P-value } \\
\hline & B & Std. Error & Beta & & \\
\hline الثيل & $\begin{array}{r}-406.909 \\
104.472\end{array}$ & $\begin{array}{r}236.057 \\
16.384\end{array}$ & .677 & $\begin{array}{r}-1.724 \\
6.377 \\
\end{array}$ & $\begin{array}{l}0.091 \\
0.000\end{array}$ \\
\hline
\end{tabular}

ويمكن كتابة معادلة الانحدار المقدرة كما يلي: قيمة التاول في قطاع الخدمات والمنتجات الصناعية والسيارات = -

$$
104.472+
$$

8/7/12 بخصوص العلاقة بين سعر الصرف وقطاع الأغذية والمشروبات: Model Summary

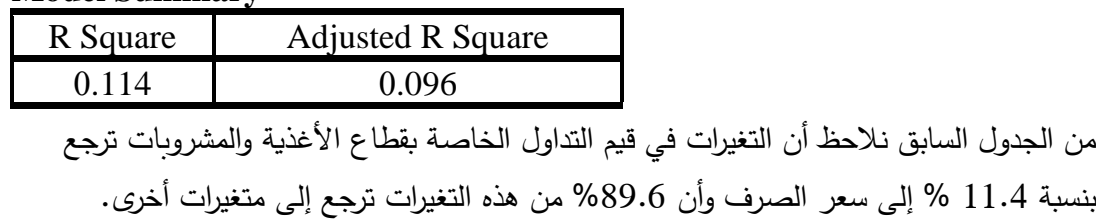

ANOVA

\begin{tabular}{|l|r|r|r|r|r|}
\hline Model & \multicolumn{1}{|c|}{ Sum of Squares } & \multicolumn{1}{c|}{ df } & Mean Square & F & P-value \\
\hline Regression & 4085401.752 & 1 & 4085401.752 & 6.179 & 0.016 \\
Residual & 31736178.665 & 48 & 661170.389 & & \\
Total & 35821580.417 & 49 & & & \\
\hline
\end{tabular}


من جدول تحليل الانحدار نلاحظ أن p-value =0.016 أي أنه يوجد أثر معنوي لسعر

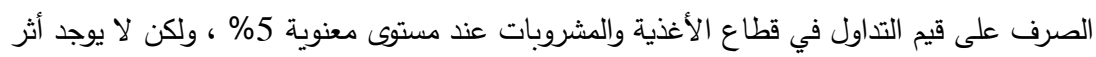

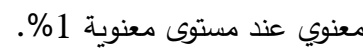
لذلك فإنتا نرفض فرضية العدم القائلة بأنه لا يوجد تأثير ذو دلالة إحصائية لسعر الصرف على قاتية تداولات قطاع الأغذية والمشروبات بالبورصة المصرية. ونقبل الفرضية البديلة القائلة بأنه يوجد تأثير ذو داتلاتلة الإدية إحصائية لسعر الصرف على قيم تداولات قطاع الأغذية والمشروبات بالبورصة المصرية.

Coefficients

\begin{tabular}{|c|c|c|c|c|}
\hline \multirow[b]{2}{*}{ Model } & \multicolumn{2}{|c|}{ Un-standardized Coefficients } & \multirow[b]{2}{*}{$\mathrm{t}$} & \multirow[b]{2}{*}{ P-value } \\
\hline & B & Std. Error & & \\
\hline 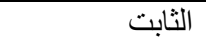 & 193.332 & 341.977 & .565 & .57 \\
\hline 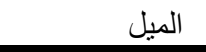 & 59.000 & 23.735 & 2.486 & .01 \\
\hline
\end{tabular}

ويمكن كتابة معادلة الانحدار المقدرة كما يلي:

قيمة التداول في قطاع الأغذية والمشروبات = 193.332 + 59 (سعر الصرف)

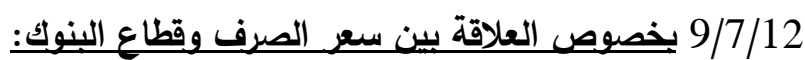

Model Summary

\begin{tabular}{|c|c|}
\hline R Square & Adjusted R Square \\
\hline 0.235 & 0.219 \\
\hline
\end{tabular}

من الجدول السابق نلاحظ أن التغيرات في قيم التداول الخاصة بقطاع البنوك ترجع بنسبة 23.5 \% إلى سعر الصرف وأن 76.5\% من هذه التغيرات ترجع إلى متغيرات أخرى.

ANOVA

\begin{tabular}{|l|r|r|r|r|r|}
\hline Model & Sum of Squares & df & Mean Square & F & $\begin{array}{c}\text { P- } \\
\text { value }\end{array}$ \\
\hline Regression & 7299358.238 & 1 & 7299358.238 & 14.726 & 0.000 \\
Residual & 23792135.631 & 48 & 495669.492 & & \\
Total & 31091493.868 & 49 & & & \\
\hline
\end{tabular}


من جدول تحليل الانحدار نلاحظ أن 0.000 - value =0 أي أنه يوجد أثر معنوي لسعر الصرف على قيم التداول في قطاع البنوك بمستوى معنوية 5\%.

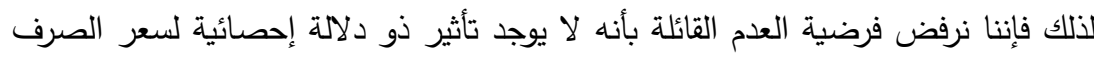
على قيم تداولات قطاع البنوك بالبورصة المصنية ترفية. ونقبل الفرضية البديلة القائلة بأنه يوجد تأثير ذو دلالة إلورئة إحصائية لسعر الصرف على قيم تداولات قطاع البنوك بالبورصة المصرية.

\section{Coefficients}

\begin{tabular}{|r|r|r|r|r|}
\hline \multirow{2}{*}{ Model } & \multicolumn{2}{|c|}{ Un-standardized Coefficients } & & \multirow{2}{*}{ P-value } \\
\cline { 2 - 4 } & \multicolumn{1}{|c|}{ B } & Std. Error & \multicolumn{1}{c|}{ t } & \multicolumn{1}{c|}{ P-var } \\
\hline & 1068.586 & 296.099 & 3.609 & 0.001 \\
& 78.863 & 20.551 & 3.837 & 0.000 \\
\hline
\end{tabular}

ويمكن كتابة معادلة الانحدار المقدرة كما يلي:

قيمة التداول في قطاع البنوك = 1068.586 + 78.863 (سعر الصرف)

10/7/12 بخصوص العلاقة بين سعر الصرف وقطاع الرعاية الصحية والأدوية: Model Summary

\begin{tabular}{|c|c|}
\hline R Square & Adjusted R Square \\
\hline 0.165 & 0.148 \\
\hline
\end{tabular}

من الجدول السابق نلاحظ أن التغيرات في قيم التداول الخاصة بقطاع الرعاية الصحية والأدوية ترجع بنسبة 16.5 \% إلى سعر الصرف وأن 83.5\% من هذه التغيرات ترجع إلى متغيرات أخرى. ANOVA

\begin{tabular}{|r|r|r|r|r|r|}
\hline Model & Sum of Squares & df & Mean Square & F & P-value \\
\hline \multirow{2}{*}{1} & 1615236.186 & 1 & 1615236.186 & 9.480 & 0.003 \\
& 8177996.631 & 48 & 170374.930 & & \\
& 9793232.818 & 49 & & & \\
\hline
\end{tabular}


من جدول تحليل الانحدار نلاحظ أن 003. = p-value أي أنه يوجد أثر معنوي لسعر الصرف على

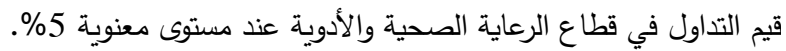
لذلك فإننا نرفض فرضية العدم القائلة بأنه لا يوجد تأثير ذو دلالة احصائية لسعر الصرف عنديه على قيه تداولات قطاع الرعاية الصحية والأدوية بالبورصة المصرية. ونقبل الفرضية البديلة القائلة بأنه يوجد تأثير ذو دلالة احصائية لسعر الصرف بالبورهل على قيم تداولات قطاع الرعاية الصحية والأدوية بالبورصة المصرية.

Coefficients

\begin{tabular}{|c|c|c|c|c|c|}
\hline \multirow[b]{2}{*}{ Model } & \multicolumn{2}{|c|}{$\begin{array}{l}\text { Un-standardized } \\
\text { Coefficients }\end{array}$} & \multirow{2}{*}{$\begin{array}{c}\begin{array}{c}\text { Standardized } \\
\text { Coefficients }\end{array} \\
\text { Beta }\end{array}$} & \multirow[b]{2}{*}{$t$} & \multirow[b]{2}{*}{ P-value } \\
\hline & B & Std. Error & & & \\
\hline الثابت & -163.926 & 173.597 & & -.944 & 0.350 \\
\hline الميل & 37.098 & 12.049 & .406 & 3.079 & .003 \\
\hline
\end{tabular}

قيمة التداول في قطاع الرعاية الصحية = -163.926 + 37.098 (سعر الصرف)

11/7/12 بخصوص العلاقة بين سعر الصرف وقطاع الموارد الأساسية: Model Summary

\begin{tabular}{|c|c|}
\hline R Square & Adjusted R Square \\
\hline 0.436 & 0.425 \\
\hline
\end{tabular}

من الجدول السابق نلاحظ أن التغيرات في قيم التداول الخاصة بقطاع الموارد الأساسية ترجع بنسبة 43.6 \% إلى سعر الصرف وأن 56.4\% من هذه التغيرات ترجع إلى متغيرات أخرى.

\begin{tabular}{|rr|r|r|r|r|c|}
\hline \multicolumn{2}{|c|}{ ANOVA } \\
Model & & Sum of Squares & df & Mean Square & F & $\begin{array}{c}\text { P- } \\
\text { value }\end{array}$ \\
\hline & n & 7724259.409 & 1 & 7724259.409 & 37.150 & 0.000 \\
& Residual & 9980182.640 & 48 & 207920.472 & & \\
Total & 17704442.049 & 49 & & & \\
\hline
\end{tabular}


من جدول تحليل الانحدار نلاحظ أن palue=0.000 أي أنه يوجد أثر معنوي لسعر p-valu

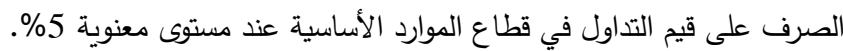

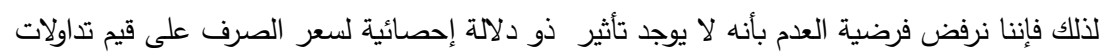
قطاع الموارد الأساسية بالبورصة المصرية. ونقبل الفرضية البيلة بأنه يوجد تأثير ذو دلالة إحصائية لسعر الصرف على قيم تداولات قطاع الموارد

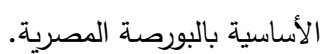

\section{Coefficients}

\begin{tabular}{|r|r|r|r|r|}
\hline \multirow{2}{*}{ Model } & \multicolumn{2}{|c|}{ Un-standardized Coefficients } & & \multirow{2}{*}{ P-value } \\
\cline { 2 - 4 } & \multicolumn{1}{|c|}{ B } & Std. Error & \multicolumn{1}{c|}{ t } & P-124 \\
\hline & -300.081 & 191.774 & -1.565 & .000 \\
\hline
\end{tabular}

ويمكن كتابة معادلة الانحدار المقدرة كما يلي: قيمة التداول في قطاع الموارد الأساسية = - 300.081 + 81.126 (سعر الصرف)

12/7/12 بخصوص العلاقة بين سعر الصرف وقطاع الكيماويات:

\section{Model Summary}

\begin{tabular}{|c|c|}
\hline R Square & Adjusted R Square \\
\hline 0.576 & 0.567 \\
\hline
\end{tabular}

من الجدول السابق نلاحظ أن التغيرات في قيم التداول الخاصة بقطاع الكيماويات ترجع بنسبة 57.6 \% إلى سعر الصرف وأن 42.4\% من هذه التغيرات ترجع إلى متغيرات أخرى.

ANOVA

\begin{tabular}{|l|r|r|r|r|r|}
\hline Model & Sum of Squares & df & Mean Square & F & P-value \\
\hline Regression & 6527514.798 & 1 & 6527514.798 & 65.294 & 0.000 \\
Residual & 4798608.626 & 48 & 99971.013 & & \\
Total & 11326123.424 & 49 & & & \\
\hline
\end{tabular}


من جدول تحليل الانحدار نلاحظ أن palue =0.000 أي أنه يوجد أثر معنوي لسعر

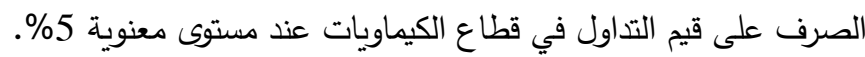
لذلك نرفض فرضية العدم بأنه لا يوجد تأثير ذو دلالة إحصائية لسعر الصرف على على قيليم تداولات قطاع الكيماويات بالبورصة المصرية. ونقبل الفرضية البديلة بأنه يوجد تأثير ذو دلالة إحصائية لسعر الصرف الكربة على قيم تداولات قطاع الكيماويات بالبورصة المصرية.

\section{Coefficients}

\begin{tabular}{|c|c|c|c|c|}
\hline \multirow[b]{2}{*}{ Model } & \multicolumn{2}{|c|}{ Un-standardized Coefficients } & \multirow[b]{2}{*}{$\mathrm{t}$} & \multirow[b]{2}{*}{ P-value } \\
\hline & B & Std. Error & & \\
\hline الثابت & -471.404 & 132.977 & -3.545 & .00 \\
\hline الميل & 74.577 & 9.229 & 8.080 & .00 \\
\hline
\end{tabular}

ويمكن كتابة معادلة الانحدار المقدرة كما يلي: قيمة التداول في قطاع الكيماويات = - 471.404 + 74.577 (سعر الصرف) يلهابهان

\section{خلاصة ما سبق من تحليل الاتحدار:}

نلاحظ أن سعر الصرف له أثر معنوي على قيم تداولات جميع القطاعات ما عالجئ عدا (

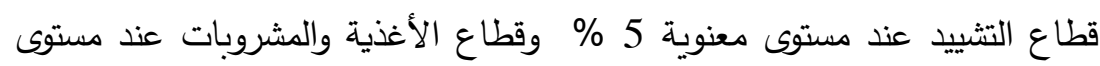

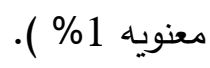
نلاحظ انخفاض قيمة R Square منخفضة وذلك لوجود متغير مستقل واحد وهو

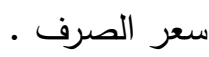


البرامج الحاسوبية المستخدمة:

$\mathbf{R}$ - version 3.5.2 -1

SPSS - version $22-2$

13 / النتائج:

1/13 يوجد تأثير ذو دلالة إحصائية لسعر الصرف على قيم تداولات قطاع الاتصالات

بالبورصة المصرية.

2/13 يوجد تأثير ذو دلالة إحصائية لسعر الصرف على قيم تداولات قطاع الخدمات

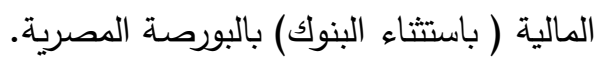

3/13 يوجد تأثير ذو دلالة إحصائية لسعر الصرف على قياء تداولات قطاع العقارات

بالبورصة المصرية.

4/13 يوجد تأثير ذو دلالة إحصائية لسعر الصرف على قيم تداولات قطاع السياحة

والترفيه بالبورصة المصرية.

5/13 لا يوجد تأثير ذو دلالة إحصائية لسعر الصرف على قيم تداولات قطاع التشييد

ومواد البناء بالبورصة المصرية.

6/13 يوجد تأثير ذو دلالة إحصائية لسعر الصرف على قيم تداولات قطاع المنتجات

المنزلية والثخصية بالبورصة المصرية.

7/13 يوجد تأثير ذو دلالة إحصائية لسعر الصرف على قيم تداولات قطاع الخدمات

والمنتجات الصناعية والسيارات بالبورصة المصرية.

8/13 يوجد تأثير ذو دلالة إحصائية لسعر الصرف على قيم تداولات قطاع الأغذية

والمشروبات بالبورصة المصرية.

9/13 يوجد تأثير ذو دلالة إحصائية لسعر الصرف على قيم تداولات قطاع البنوك

بالبورصة المصرية.

10/13 يوجد تأثير ذو دلالة إحصائية لسعر الصرف على قيم تداولات قطاع الرعاية

الصحية والأدوية بالبورصة المصرية. 
11/13 يوجد تأثير ذو دلالة إحصائية لسعر الصرف على قيم تداولات قطاع الموارد الأساسية بالبورصة المصرية. 12/13 يوجد تأثير ذو دلالة إحصائية لسعر الصرف على قيم تداولات قطاع الكيماويات بالبورصة المصرية. 14 / التوصيات: - (11

1/14 تحقيق استقرار سعر الصرف عن طريق السياسات الاقتصاديات وبكافة

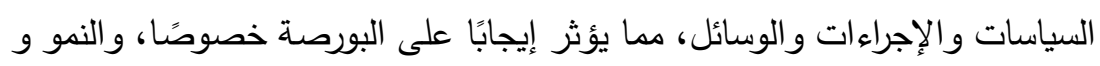
الاستقرار الاقتصادي عمومًا. 2/14 تنويع مصادر النقد الأجنبي وبالأخص تحويلات المصريين بالخارج عبر قنوات رسمية. 3/14 أن يكون سعر الصرف واقعيًا يعكس قوى العرض والطلب، حيث أن التعويم

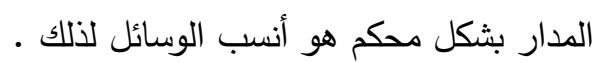
4/14 يجب على السلطات المصرية اتخاذ كافة التدابير التي تضمن سعر موحد للجنيه المصري وعدم وجود أكثر من سعر صرف في السوق. 5/14 الحد قدر الإمكان من عملية تخفيض قيمة العملة بشكل متكرر لأنه يجعل من فئل

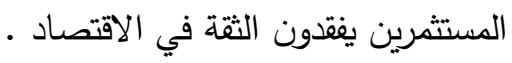
6/14 يجب أن تكون عملية تدفق رؤوس الأموال الأجنبية إلى الداخل عملية مدروسة حتى لا تحدث عملية سيطرة للمستثمرين الأجانب على مفاصل الاقتصاد. 7/14 القيام بإصلاحات جذرية للقطاع المصرفي المصري حتى يستطيع مواكبة نظرائه في الدول الأكثر تقدمًا، حتى يجد المستثمرون الأجانب مصارف تعمل بنفس المعايير التي يجدونها في الدول المتقدمة. 8/14 العمل على إيجاد أساليب جديده لتحديد سعر الصرف في مقابل سلة عملات وليس عملة واحدة فقط. 
9/14 العمل على تتويع مصادر الدخل من العملات الأجنبية ومحاولة زيادة المعروض العاد من العملات الأجنبية في النظام المصرفي.

10/14 الاستمرار في سياسة التحرير لسعر الصرف عن طريق التعويم المدار، مما يساعد على خلق التدابير اللازمة لمجابهة أي مشكلة متعلقة بندرة العملة الأجنبية.

\section{المراجع}

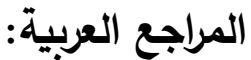

o الأسدي، صباح رحيم مهدى و الربيعي، رجاء خضير عبود, " اثر حركة أسعار

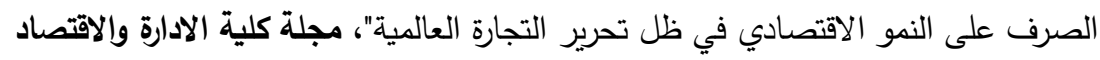
للاراسات الاقتصادية والادارية والمالية, مجلد5, العدد 2جامعة بابل، العراق، 2013,

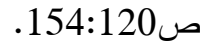

o الباجوري, خالد عبد الوهاب البنداري، " تأثير الفروق في أسعار صرف الجنيه المصري على الاقتصاد المصري "، بحث منشور، اتحاد الغرف العربية، 2016.

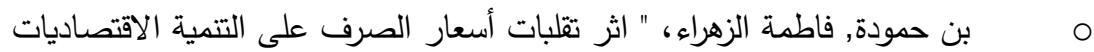

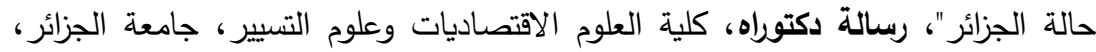
2009, ص20 200

O مامد، صلاح الدين "أسعار صرف العملات، مجلة إضاءات مالية ومصرفية، معهد الدراسات المصرفية، الكويت، العدد 12، 2011، صاين 2. O خرباش، منية, " أثر مخاطر سعر الصرف على أداء محفظة الأوراق المالية"،

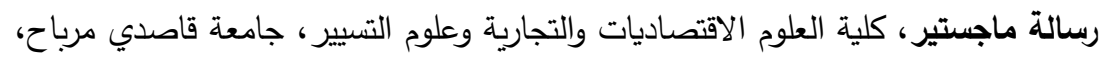

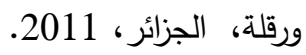
م الداوي, اليامنة، أثر سعر الصرف على التجارة الخارجية (دراسة حالة الجزائر للفترة

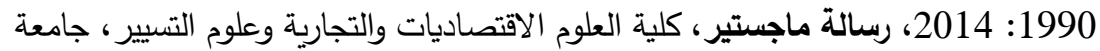
قاصدي مرباح، ورقلة، الجزائر، 2015. 
م درقال, يمينة، " دراسة تقلبات أسعار الصرف في المدى القصير، اختبار فرضية التعديل الزائد في دول الدغرب العربي"، رسالة ماجستير منشورة، كلية العلوم الاقتصاديات

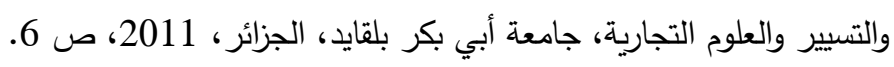

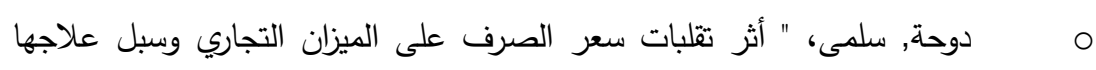

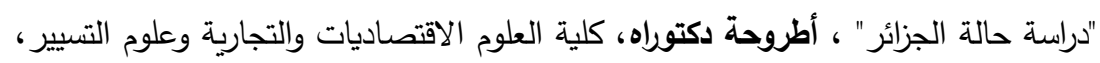

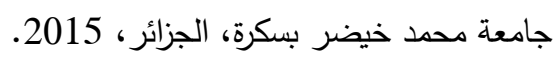

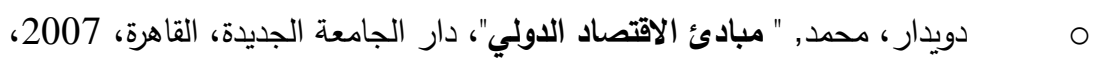
ص 68.

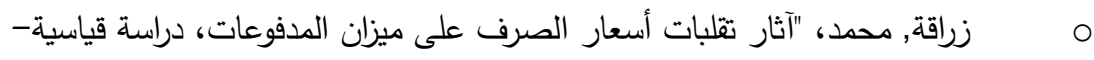

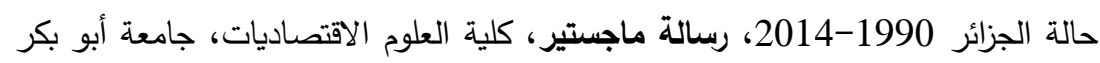
بلقايد، الجزائر ، 2016, صائر الجن

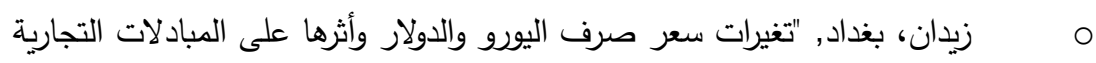

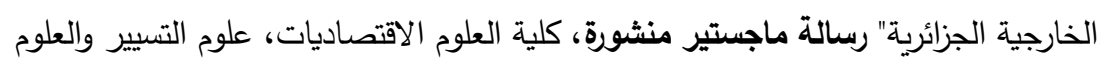

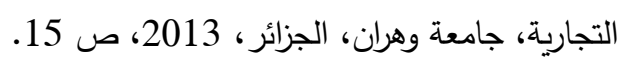

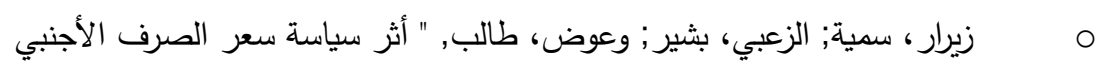

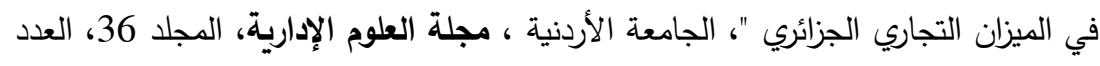
2، 2009.

o

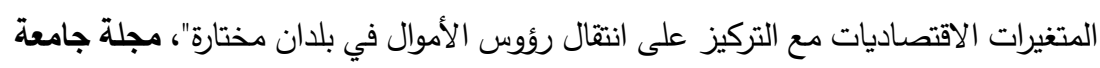

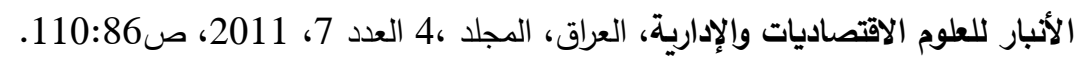

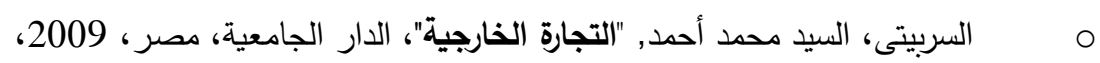
ص 246. O عباس، عباس فؤاد وعبد الله، سعد بن على, "تأثير التغير في أسعار صرف العملات

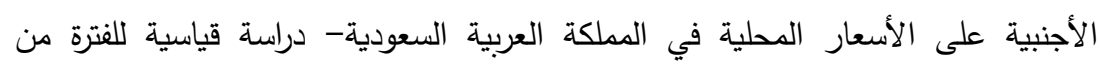

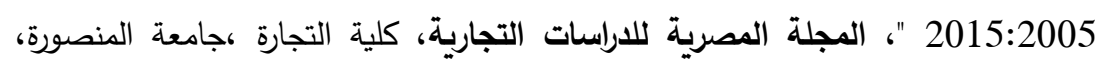

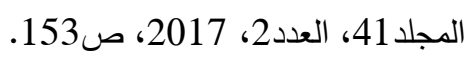


O عبد الحسن، عبد الحسين جليل, "سعر الصرف وإدارته في ظل الصمات الاقتصادي (نظرية وتطبيقات)"، الطبعة الأولى، دار صفاء للطباعة والنشر والتوزيع، عمان، الأردن، 2011، ص ص 91.

O م ع ماري، علاء الدين وبوناصري، حكيم, " أثر تقلبات أسعار الصرف على ميزان المدفوعات الجزائري "، مذكرة مقدمة لاستكمال متطلبات شهادة ماستر أكاديمي، كلية العلوم الاقتصاديات والعلوم التجارية وعلوم التسيير ، جامعة العربي التبسي- تبسة، الجزائر، 2016. O موض الله, زينب حسن ، العلاقات الاقتصاديات الدولية، دار الجامعة الجديدة، الإسكندرية، 2008، ص44.

O م مخرى, نعمة سمير ، "العلاقة التبادلية بين سعر الصرف وسعر الفائدة وانعكاساتها على ميزان المدفوعات"، دار اليازوري للنشر والتوزيع، الطبعة العربية، الأردن، 2011،

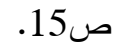
م مانة، الطاهر "(قتصاديات صرف النقود والعملات"، دار الخلدونية، الجزائر، 2009، ص10

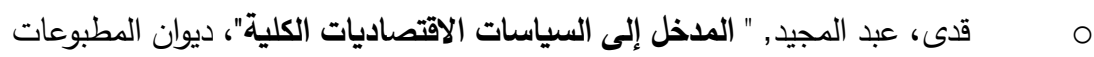

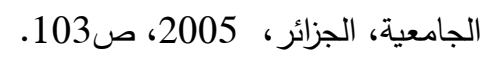
م محمد, أحمد عبد الموجود، " تقلبات سعر صرف الدولار"، دار التعليم الجامعي

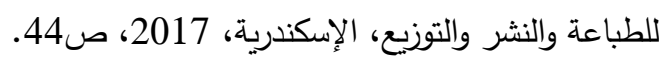
O م محد، جبورى, " تأثير أسعار الصرف على التضخم والنمو الاقتصادي: دراسة نظرية وقياسية باستخدام بيانات بانل"، رسالة دكتوراه منشورة، كلية العلوم الاقتصاديات وعلوم التسيير والعلوم التجارية، جامعة أبى بكر بلقايد تلمسان، الجزائر، 2013 ،ص28.

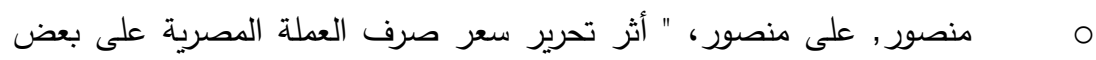
مؤشرات الاقتصاد المصري"، مجلة مصر المعاصرة، الجمعية المصرية للاقتصاد السياسي والإحصاء والتشربع، مؤترات الإدساد. O موسى, شقيري نورى وآخرون، " التمويل الاولي ونظريات التجارة الخارجية"، دار

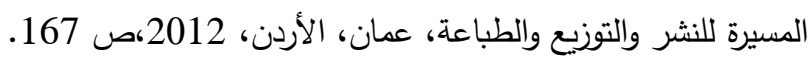




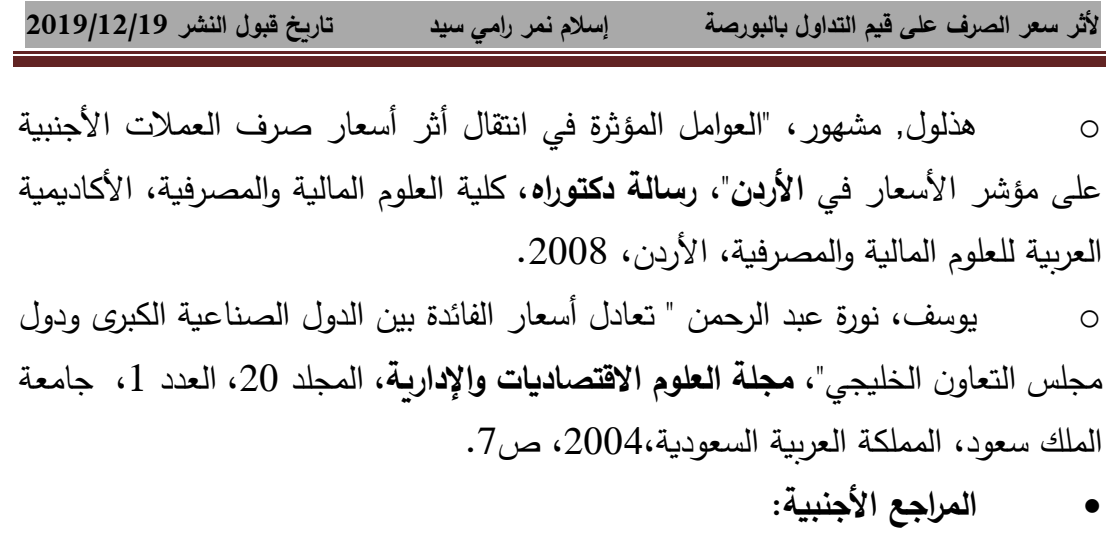

○ Amador, Octavio Fernández; Gächter,Martin; Larch, Martin and Peter، Georg, "Does monetary policy determine stock market liquidity? New evidence from the euro zone", Journal of Empirical Finance Vol 21, 2013.

- Auboin, Marc and Ruta, Michele "the relationship between exchange rates and international trade: a review of economic literature", World Trade Organization، Economic Research and Statistics Division,27 October 2011.

○ barguellil, Achouak; Ben-Salha, and Zmami, Ousama Mourad, "Exchange rate volatility and economic growth", Journal of Economic Integration, Vol.33, No.2, 2018, pp.1302:1336.

- Cassino, Enzo and Oxley, David " Exchange rate valuation and its impact on the real economy", This paper has been prepared for a joint Reserve Bank-Treasury Forum on the Exchange Rate, Wellington, 26 March 2013.

- Korkmaz, Suna "The effect of exchange rate on economic growth", Balikesir University, Bandirma Faculty of Economics and Administrative Sciences، Department of Economics, 2015.

○ Madura, Jeff، "International corporate finance"، $8^{\text {th }}$ edition، Thomson South- Western، U.S.A، 2006 ‘p87.

○ Mishkin, F.S.، "Economics of money، banking، and Financial Markets" ، 9 edition، prentice Hall، 2009، p441.

○ Musyoki1, Danson; Pokhariyal, Ganesh P. and Pundo, Moses, "The impact of real exchange rate volatility on economic growth: Kenyan evidence", Business and Economic Horizons, Vol 7, Issue 1, June 2012, pp. 59-75. 
- Šimakova, Jana, "The Impact of Exchange Rate Movements on Firm Value in Visegrad Countries", Acta Universitatis Agriculturae et Silviculturae Mendelianae Brunensis, vol 65Issue 6,2016, pp 2105 $-2111$.

- Twarowska, Katarzyna, "The Impact of Exchange Rate on Poland's Trade Flows", International Journal of Management Knowledge and Learning, vol 4، Issue 1, 2015, pp 41-57 . 